\title{
FORMAS DE EROSION EN EL FLYSCH EOCENO SURPIRENAICO
}

\author{
José M. García-Ruiz* \\ Juan Puigdefábregas-Tomás**
}

\begin{abstract}
RESUMEN
En el flysch eoceno de la vertiente meridional de los Pirineos tienen lugar importantes procesos de erosión ligados a dos grandes sistemas morfogenéticos, uno pluvial y otro relacionado más con las características de la fusión de la nieve. El tránsito entre ambos sistemas se opera alrededor de los $1.600 \mathrm{~m}$. de altitud. Las formas de erosión (vertientes con arroyamiento difuso, desprendimientos, solifluxión, rigolas, cabeceras activas de torrentes...), se han puesto de manifiesto en un mapa geomorfológico y se han relacionado estadisticamente con la pendiente, la exposición, la altitud y la cobertera forestal. Estos factores controlan en buena parte la distribución de cada forma de erosión, si bien la acción humana tiene asimismo una gran importancia, sobre todo entre 600 y $1.200 \mathrm{~m}$. de altitud. Los autores analizan finalmente algunos aspectos funcionales de las distintas formas de erosión, integrándolas en tres ambientes clásicos dentro del flysch: las vertientes supraforestales, el bosque y las áreas degradadas y con cultivos abandonados.
\end{abstract}

\section{SUMMARY}

FORMS OF EROSION IN THE SOUTH PYRENEAN EOCEN FLYSCH. In the eocen flysch of the Pyrenees southern slope there are important processes of erosion which take place owing to two great morphogenetic systems; one of them is related to the action of the rain and the other one to the peculiar characteristics of the snowmelt. The evolution from one system to the other occurs at a

* Departamento de Geografía. Colegio Universitario de La Rioja, Logroño.

** Centro Pirenaico de Biología Experimental. Jaca (Huesca). 
height of $1.600 \mathrm{~m}$. approximately. The forms of erosion (slopes with difuse overland flow, landslides, solifluction, rills, active springs heads...) are shown in a geomorphologic map and have been statistically related with the gradient, the exposition, the height and the vegetation cover. These elements control to a great extent the distribution of each form of erosion although the human action also has great importance, above all between 600 and $1.200 \mathrm{~m}$. Finally, the authors analyse some functional aspects of the different forms of erosion, integrating them in three classical types of environment within the flysch: the supraforestal slopes, the forest and the degraded and abandoned areas.

En la vertiente meridional del Pirineo español, las diferentes unidades estructurales se disponen en bandas alargadas en sentido W-E, cuya morfología y respuesta frente a los agentes de erosión aparecen bien individualizadas. Al Sur de las Sierras Interiores, esencialmente calcáreaś, y al Norte de la depresión interior, margosa, el flysch ocupa una serie de alineaciones montañosas cuya altitud desciende suavemente hacia el Sur desde unos 2.100-2.200 m. hasta 600-800 m.

La diferencia altitudinal entre el límite septentrional y el meridional origina una gran diversidad de sistemas de erosión y transporte en función de la variación climática, la vegetación y los usos del suelo, de forma que se establece una amplia gama morfoclimática desde ambientes que rozan el límite de lo periglaciar hasta otros francamente submediterráneos. Ello tiene mayor interés por cuanto el flysch se comporta como un material homogéneo en el que tan sólo destacan algunos bancos potentes de calizas. De ahí que podamos establecer como objetivos:

1. Identificar los problemas de erosión más destacados en el flysch.

2. Relacionar la distribución espacial de las formas de erosión con variables topográficas y de uso del suelo.

Conviene aclarar que el presente estudio se refiere fundamentalmente a formas de erosión actuales y subactuales y que sólo se alude a paleoformas cuando así lo exige la explicación de procesos actuales.

Espacialmente, el estudio se centra en una región de flysch comprendida entre las cuencas de los ríos Veral, al W, y Gállego, al E. Hace algunos años, BARRERE (1966) publicó un estudio sobre la 
morfología de parte de esta región, con alusiones a la dinámica actual de vertientes y en su haber cabe señalar una serie de mapas que en parte coinciden con los límites del área analizada, aunque sus objetivos y plasmación cartográfica son bien diferentes.

\section{Morfología general del Flysch}

La facies flysch del Eoceno, bien representada en el Pirineo español, posee una potencia de 3.500-4.500 m. (Cuisiense y Luteciense), con intercalaciones de grandes ritmos calcáreos y areniscosos, que permiten desentrañar las líneas generales de una tectónica muy compleja (SOLER y PUIGDEFABREGAS, 1970). Hacia el sur, el flysch pasa lateralmente a margas.

En el Pirineo meridional la tectónica se resuelve durante el plegamiento alpino mediante escamas de corrimiento que en el flysch, por su plasticidad, originan pliegues muy apretados y fallados, en sentido WNW-ESE, con una estructura que se sigue muy difícilmente. Como el flysch, a pesar de su alternancia en estratos breves de calizas $o$ areniscas $y$. margas, reacciona muy homogéneamente a la erosión, la estructura desempeña un papel poco destacado; no obstante, análisis de detalle muestran la existencia de cierto control estructural de algunos procesos erosivos, principalmente los movimientos en masa.

El relieve se resuelve en una serie de colinas y alineaciones de cumbres redondeadas y vertientes muy homogéneas, salvo allí donde afloran estratos más potentes de areniscas o calizas intercalados en el flysch; en ese caso se forman relieves en cuesta con frentes a veces espectaculares y tanto más frecuentes cuanto más al $\mathrm{W}$ de la región estudiada, donde llegan a formar profundos cañones al ser atravesados por la red fluvial. En el resto, los valles aparecen formados por vertientes -a veces regularizadas- con una pendiente entre 30 y $60 \%$. En ellas se insinuan con frecuencia relieves más suaves, de cronología difícil de precisar, pero sin duda pertenecientes a un Cuaternario muy antiguo dada su posición topográfica. Destacan entre ellos los relieves maduros de Cillas, Cortillas y Bescós.

Esencialmente, la evolución de vertientes en el flysch está relacionada con una acción fluvial de muy diversa magnitud y con deslizamientos en masa. La acción glaciar no tuvo aquí apenas importancia, pues la zona de circos se limitaba al Pirineo axil y a las 
cabeceras de las Sierras Interiores. En estas últimas y muy cerca del contacto con el flysch se formaron ocasionalmente pequeños glaciares, a veces quizás funcionando como glaciares rocosos, que dejaron sobre aquél potentes acumulaciones morrénicas de forma un tanto caótica. Los únicos ejemplos de valles glaciares nacían más al $\mathrm{N}$ y al llegar al flysch formaron excelentes ejemplos de valles en artesa cuyo mejor exponente es el valle del Gállego. Una serie de arcos morrénicos representan estadios glaciares de dudosa adscripción cronológica, siendo los de Aragón (Castiello de Jaca) y el terminal del Gállego (Senegüé) los mejor estudiados (BARRERE, 1963; MARTI BONO, 1977; MARTI BONO, SERRAT y GONZALEZ, 1978). Por su interés morfológico posterior conviene resaltar la presencia de potentes morrenas laterales que, con frecuencia, obturaban valles afluentes; en estos últimos tuvieron lugar procesos de acumulación que culminaron con la formación de rellanos de obturación, algunos de los cuales están hoy bien conservados. En el postglaciar los muros morrénicos fueron atravesados por los barrancos afluentes, lo que permitió la reactivación de la erosión en buena parte del territorio y la formación de grandes conos de deyección, parcialmente funcionales hoy, al desembocar en el valle principal (sobre todo en el Gállego). Durante el Holoceno, toda la red fluvial, en general, ha experimentado un proceso de encajamiento.

Se ha elaborado un mapa geomorfológico que tiene por objeto destacar los aspectos más importantes de la dinámica actual de vertientes y establecer relaciones con diversas variables ambientales. En dicho mapa se recogen:

- los relieves estructurales más destacados en el conjunto del flysch,

- las formas ligadas directa o indirectamente a la acción glaciar (morrenas, rellanos de obturación) y fluvial (valles anastomosados, conos de deyección funcionales o no), aunque sin entrar en discusiones acerca de su cronología,

- las formas de erosición actuales y subactuales, que son las que han recibido por nuestra parte un tratamiento estadístico más intenso.

Dado que alguna de estas últimas formas poseen una terminología difícil de precisar, se incluye a continuación una breve descripción de las mismas.

Cuencas de recepción activas. Corresponden a cabaceras funcio- 
nales de barrancos, con suelo inexistente y fuerte pendiente, llegando a originar en algunos casos fenómenos de acarcavamiento. A partir de estas cuencas suele salir un canal de desagüe encajado, aunque a veces este último no existe y la cuenca de recepción desemboca directamente en un barranco.

Vertientes desnudas sin red jerarquizada, con gran erosión laminar (erosión muy severa). Llamamos así a aquellas vertientes en las que no hay incisiones por abarrancamiento pero en las que el suelo ha desaparecido por completo hasta hacer aflorar a la roca madre en superficie. Procesos intensos de solifluxión y deslizamiento son los responsables de la situación actual. Se hallan situadas cerca de las divisorias y en relación, a veces, con cabeceras activas de torrentes.

Solifluxión. Incluimos aquí el término solifluxión en un sentido amplio, pues acoge tanto a los desplazamientos lentos del suelo, sin originar cicatrices pero con lóbulos que accidentan suavamente las vertientes, como a los deslizamientos, más rápidos y con formación de nichos. En uno y otro caso se dan sobre los suelos profundos y ricos en material fino de los sectores elevados del flysch; ambos procesos pueden o no coexistir, aunque en la actualidad predominan los deslizamientos sobre la solifluxión clásica.

Desprendimientos. Son formas de mayores dimensiones que los deslizamientos anteriores. Dan lugar a un gran nicho de arranque de materiales y al pie a un lóbulo de acumulación que adquiere las características de una colada de barro. Afectan al suelo, derrubios $y$ en ocasiones incluso al sustrato.

Rigolas (Rills). Cerca de la línea de cumbres, los suelos profundos pueden verse afectados por un proceso de rigolización, que origina la aparición de numerosas líneas de drenaje paralelas unas a otras $\mathrm{y}$ muy próximas pero sin llegar a integrarse. $\mathrm{Su}$ profundidad no supera los $50-100 \mathrm{~cm}$. y probablemente son subactuales.

En los tramos bajos del flysch también se originan rigolas aunque de características diferentes a las anteriores: son aún más superficiales, más funcionales en la actualidad y, desde luego, son menos rectilíneas debido a la divergencia de flujo provocada por las piedras y los arbustos.

Laderas con arroyamiento difuso, áreas de arranque y pequeñas incisiones (erosión severa). Predomina en ellas la erosión laminar, con minúsculas rigolas cambiantes cada poco tiempo, algunos movimientos masivos superficiales de pequeña magnitud e incisiones generadas 
por barrancos aislados y que no llegan a constituir un problema general. El suelo, por esa erosión laminar ha perdido buena parte de la fracción fina y es, por tanto, muy pedregoso.

Areas dominadas por movimientos en masa de escasa entidad y erosión moderada. Son áreas donde se conserva bien la capa superficial del suelo. No hay señales de abarrancamiento ni los desprendimientos tienen lugar con frecuencia, aunque dentro del bosque puede darse una reptación importante a largo plazo y formación de canales de drenaje poco profundos.

Además de las formas anteriores, cuya dinámica es activa hoy en la mayoría de los casos, hay otras, más antiguas, con notable interés morfológico por su situación y repercusiones en la evolución posterior del relieve. Entre ellas destacamos:

Valles "en cuchara". Poseen la forma de valles en cuna, más anchos que profundos y con vertientes que enlazan suavemente con el eje de drenaje; sin embargo, cuentan con una pendiente longitudinal muy superior, prácticamente paralela a la de la vertiente en que se inscriben y tienden a ser algo más anchos en cabecera aunque no poseen auténtica cuenca de recepción. Son, en todo caso, de pequeñas dimensiones, pues no superan los $700 \mathrm{~m}$. de longitud y 200-300 m. de anchura. Algunas de las vertientes bajas más occidentales aparecen afectadas totalmente por este tipo de valles que son, sin duda, formas fósiles. Corresponden, no obstante, a un Cuaternario reciente por su situación topográfica.

Rellanos colgados. Coinciden generalmente con antiguas cuencas de recepción, de formas suaves y amplias y en cuyo fondo se han acumulado potentes espesores de materiales por solifluxión; también se asimilan a hombreras o rellanos laterales de valles antiguos sobre los que se ha inscrito más recientemente la red fluvial. Se encuentran a diferentes niveles y nunca alcanzan grandes dimensiones; son más frecuentes en el borde meridional del flysch y al SE de la región estudiada.

Vertientes regularizadas. Son vertientes rectilíneas situadas en torno a las líneas de cumbres, con una pendiente entre 35 y $40^{\circ}$ y que cronológicamente se atribuyen al Würn en el Pirineo oriental (SOUTADE, 1973) aunque BARRERE (1966) sugiere que pueden ser incluso villafranquienses, al menos las más elevadas. Algunas de ellas se encuentran en pleno proceso de degradación por la acción de barrancos, y así se ha hecho constar en el mapa. Parte de estas 
vertientes se encuentran cubiertas por un suelo profundo de alteración sometido hoy a diversos procesos de erosión. Desaparecido este suelo, la vertiente sigue evolucionando por regularización. En las partes bajas, junto a los ríos y barrancos, también aparecen vertientes regularizadas, aunque poseen más pendiente $\left(45-50^{\circ}\right)$ y los suelos son más esqueléticos; adquieren la forma de facetas triangulares (BARRERE, 1966).

\section{El clima}

El ambiente climático del flysch se halla muy condicionado por su situación en el flanco meridional de las Sierras Interiores. Estas sierras forman potentes relieves $(2.500-2.800 \mathrm{~m}$. s/M) con dirección general E-W, de manera que inducen cierto efecto föhn sobre el flujo predominante del NW. Al norte de ellas encontramos condiciones de montaña oceánica, con precipitación abundante y nieblas frecuentes; al sur, en nuestra región, aparece un clima submediterráneo con fuertes contrastes térmicos, una punta de sequía estival centrada en julio y dos máximos pluviométricos, uno en mayo y otro en noviembre.

Los resultados obtenidos por diversos autores (LISO y ASCASO, 1969; PUIGDEFABREGAS y CREUS, 1976; DE LEON et al, 1976; CREUS, 1977) permiten indicar que la banda altitudinal con mayor superficie en el flysch, entre 1.000 y $1.100 \mathrm{~m}$. s/M, recibe también entre 1.000 y $1.100 \mathrm{~mm}$. anuales de precipitación; su temperatura media anual oscila entre 9 y $10^{\circ} \mathrm{C}$. El mes de julio suele dar las temperaturas máximas, $26-28^{\circ} \mathrm{C}$ como promedio, con precipitaciones que oscilan entre 25 y $40 \mathrm{~mm}$. Los inviernos son moderados, con media de las temperaturas mínimas del mes más frío entre -1 y $-3^{\circ} \mathrm{C}$.

Existen dos factores que modifican el esquema climático anterior, uno es la altitud y otro la longitud geográfica. Ambos imponen los principales gradientes que condicionan la variación del clima a escala regional.

El ascenso altitudinal se acompaña por un aumento de precipitación y una disminución de la temperatura media. La primera sigue aproximadamente a la altitud en valor absoluto, de manera que, en la parte más alta, son de esperar unos $2.000 \mathrm{~mm}$. anuales. La segunda disminuye a razón de $0,5^{\circ} \mathrm{C} / 100 \mathrm{~m}$., de manera que a los $2.000 \mathrm{~m}$. $\mathrm{s} / \mathrm{M}$ se deben rozar $\operatorname{los} 5^{\circ} \mathrm{C}$ de temperatura anual media (PUIGDE- 
RELACION ENTRE EL PORCENTAJE DE PRECIPITACION NIVOSA SOBRE LA TOTAL DE DICIEMBRE A MARZO Y LA ALTITUD. (Datos correspondientes al periodo 1970-73)

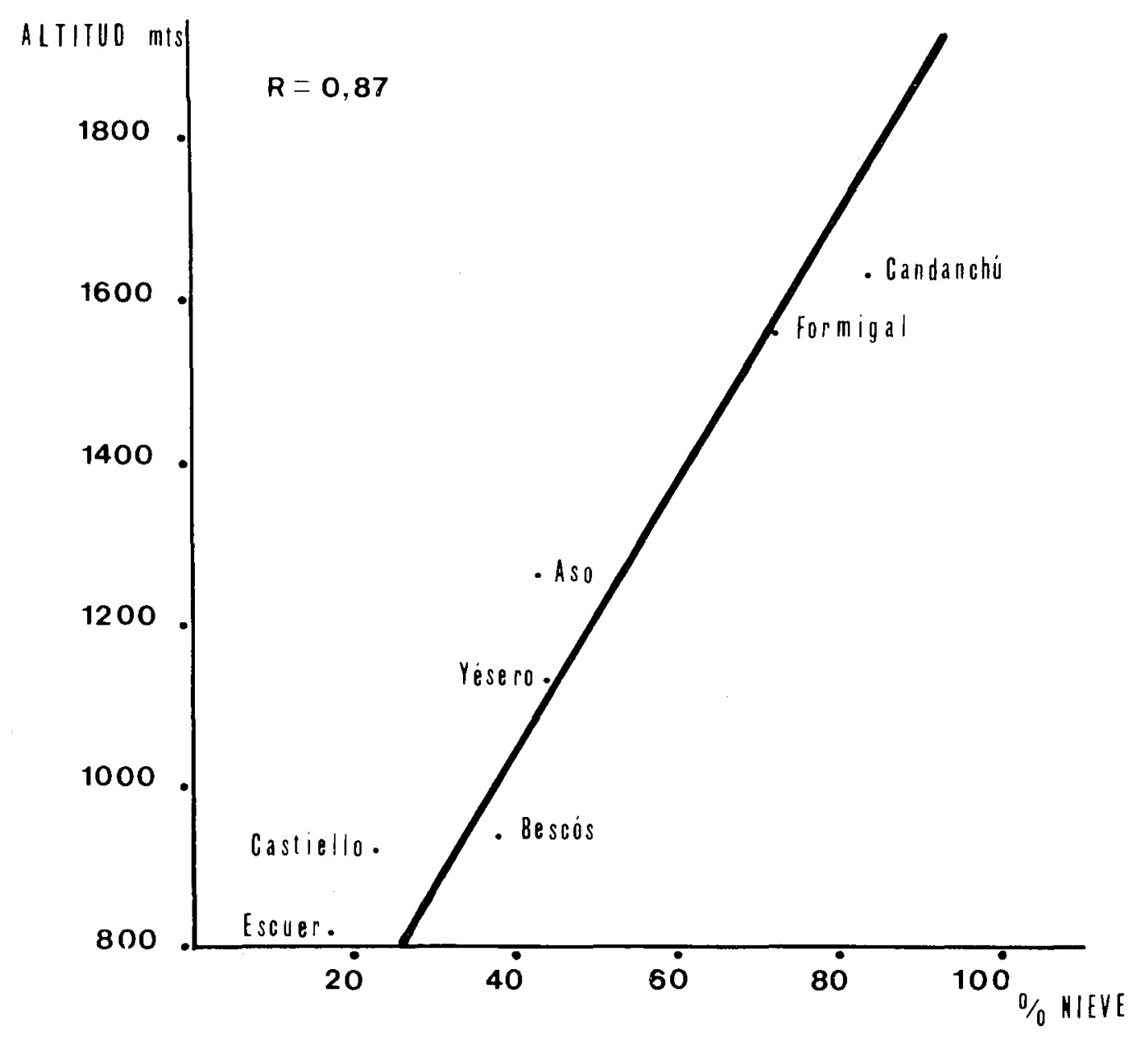

FIG. 1 
FABREGAS, 1969). La isoterma $0^{\circ} \mathrm{C}$ para el período diciembremarzo se sitúa alrededor de $1.600 \mathrm{~m}$. s/M (GARCIA-RUIZ et al. en prensa), de manera que a partir de esa cota, la precipitación nivosa adquiere verdadera importancia. De todos modos, la innivación no llega a excluir completamente a la lluvia. La fig. 1 muestra que a $1.600 \mathrm{~m}$. se da todavía un $30 \%$ de precipitación líquida durante los meses diciembre-marzo, hecho que, como veremos tiene una considerable importancia geomorfológica.

El gradiente climático E-W expresa el cambio de las condiciones continentales, propias del Pirineo central, a las más oceánicas del Pirineo Navarro (CREUS, 1977). El máximo pluviométrico pasa de mayo a noviembre, se acusa la punta de sequía estival, mientras aumenta la importancia de la precipitación nivosa. La temperatura tiende a descender reduciéndose la duración del período vegetativo, probablemente debido a que la mayor humedad del suelo retrasa el calen tamiento primaveral.

Superpuestos a los dos gradientes regionales que acabamos de describir, existen factores topográficos que configuran el detalle de los mosaicos climáticós en paisaje real. Por su importancia, mencionaremos dos: las depresiones y la exposición de las laderas.

Las depresiones tienden a retener corrientes nocturnas de densidad originando fuertes inversiones de temperatura. El fenómeno se manifiesta en la depresión media y en el fondo de los grandes valles que surcan transversalmente nuestra región. Se han detectado gradientes verticales medios entre 2 y $3^{\circ} \mathrm{C} / 100 \mathrm{~m}$., situándose la faja térmica alrededor de $250 \mathrm{~m}$. sobre el fondo del valle (PUIGDEFABREGAS, 1970).

En cuanto a la exposición de las laderas podemos distinguir dos aspectos: el primero, las diferencias entre solanas y umbrías; el segundo, la situación respecto al flujo predominante del NW.

El carácter continentalizado de las solanas respecto al clima de las umbrías, más regulado (PUIGDEFABREGAS y CREUS, 1978), se acentúa en nuestra región debido a las diferencias de vegetación. En las solanas abundan los yermos y campos abandonados, suelos pedregosos con escasa capacidad de almacenamiento hídrico. En las umbrias, dominan suelos forestales, cubiertos de pinares. Por encima de la cota $1.600 \mathrm{~m}$., los contrastes solana-umbría se traducen en un diferente comportamiento del manto nivoso. Este último, en las solanas puede dislocarse ya en enero o febrero, favoreciendo un 
periglaciarismo suave en los rodales desnevados. El hielo en el suelo es muy superficial, no superando los $10 \mathrm{~cm}$. según nuestras observaciones en Sayerri, a $1.800 \mathrm{~m}$. s/M durante el invierno de 1982. En comparación con la zona axil pirenaica, al norte de las sierras in teriores, con gran innivación y fusión tardía y rápida, las vertientes altas del flysch se distinguen por su escasa innivación con fusión lenta y precoz, sobre todo en las solanas.

La orientación de las vertientes al W y NW viene acompañada de una mayor precipitación durante el paso de perturbaciones oceánicas que se traduce en mayores pluviometrías a fin de otoño (PUIGDEFABREGAS y CREUS, 1976 y CREUS, 1977).

Un último aspecto climático que vamos a comentar brevemente por su importancia en el proceso erosivo es la intensidad de la precipitación. Sólo disponemos de información pluviográfica del observatorio de Jaca (CREUS y PUIGDEFABREGAS, 1978), pero tanto estos datos como los resultados de ELIAS (1963), muestran que nuestra región se encuentra en una zona de intensidades relativamente suaves frente a las que se detectan en las cabeceras adyacentes del Cinca y del Irati. Considerando intervalos de una hora y períodos de retorno de 10 años, encontramos valores de $37 \mathrm{~mm}$. en Jaca, frente a los $50-60 \mathrm{~mm}$. de las cabeceras mencionadas. Para intervalos de 24 horas se observan valores decrecientes de este a oeste: Gállego, $96 \mathrm{~mm}$. (Biescas); Aragón, $79 \mathrm{~mm}$. (Villanúa); Esca, $60 \mathrm{~mm}$. (Isaba), inferiores a los $110 \mathrm{~mm}$. del Cinca e Irati. Si aumentamos el intervalo a 8 días, manteniendo el mismo período de retorno, los máximos aumentan a $160 \mathrm{~mm}$. para Artieda a $652 \mathrm{~m}$. s/M, $240 \mathrm{~mm}$. para Biescas a $875 \mathrm{~m}$. s/M y $380 \mathrm{~mm}$. para Candanchú a $1.650 \mathrm{~m}$. s/M. ya al norte de las sierras interiores.

Los grandes aguaceros no se producen al azar en cualquier época del año, sino que muestran preferencia por dos épocas, una a fines de verano (septiembre) y otra en otoño (noviembre), siendo la segunda la que alcanza mayores porcentajes de ocurrencia.

\section{Vegetación y uso del suelo}

El paisaje vegetal de la región estudiada ha sufrido intensas modificaciones por acción del hombre. Podemos distinguir en él cuatro grandes categorías: 1) cultivos actuales, 2) matorrales y cultivos abandonados, 3) bosques, y 4) pastos de alta montaña utilizados 
por el ganado en verano.

Cultivos actuales.-Comprenden unas 6.500 ha., lo que representa apenas un $7 \%$ de la superficie total de la región. No suelen sobrepasar los $1.200 \mathrm{~m}$. de altitud ni las pendientes superiores al $30 \%$. Se localizan en áreas coluviales al pie de laderas, terrazas fluviales y rellanos o llanuras de obturación glaciar. Predomina la gestión cerealista, aunque en la última situación geomorfológica es frecuente la rotación con alfalfas, prados de siega y patata.

Matorrales y cultivos abandonados. -Constituyen un paisaje abigarrado en mosaico que se extiende por las vertientes menos umbrosas, ascendiendo hasta los $1.500 \mathrm{~m}$. de altitud. Los antiguos cultivos representan una colonización de interfluvio, sobre todo en el sector oriental de la región, seleccionando las lomas divisorias y relieves maduros. En tales condiciones aparecen restos de complejos sitemas de abancalamiento (Cillas, Cortillas, Ainielle), cuyo grado de elaboración disminuye mucho al oeste del Gállego.

Las parcelas aparecen hoy en diversos estadios sucesionales según la época de su abandono. Una vez superada la fase más efímera de anuales, podemos distinguir las siguientes etapas:

1.--Pastos secos de Brachypodium ramosum, Festuca ovina, Koeleria vallesiana, con rodales de Brachypodium pinnatum en afloramientos temporales de agua subcortical.

2.-Matorral de Genista scorpius que, a modo de aureola, invade las parcelas desde los bordes al centro.

3.-Matorral de boj, Echinospartium horridum, Ononis fruticosa, Aphyllantes monspelliensis.

4.-Progresiva entrada de Pinus sylvestris en forma de bosque abierto.

Las dos últimas se confunden ya con los matorrales en laderas más pendientes o suelos esqueléticos sobre barras calizas, que sin llegar a ser cultivados fueron tradicionalmente objeto de un intenso pastoreo con ganado lanar y caprino. En tales condiciones y en la parte baja de la región, es frecuente observar formaciones arbustivas de boj con carrascas (Quercus ilex ssp. rotundifolia).

Gran parte de estos yermos y matorrales fue repoblada en la década 1955-1965. La superficie afectada puede evaluarse en unas 9.200 ha, cifra que representa el $10 \%$ de la totalidad de la región. La mayor parte de la repoblación se realizó con Pinus nigra y las 
técnicas fueron variando con el tiempo; al principio se utilizaban hoyos y fajas excavadas mediante tracción animal, mientras que al final se utilizaron ya medios mecánicos para construir grandes bancales.

Los lechos de inundación de los principales ríos se colonizan por comunidades de sauces muy fragmentadas (Salix purpurea, S. eleagnos), a las que suceden Pinus Sylvestris chaparro con Berberis vulgaris e Hypopheae rhamnoides en los conos de deyección y cascajos menos afectados por las avenidas.

Bosques.-La superficie forestada representa una tercera parte del total regional y en ella predominan los pinares de Pinus sylvestris. Estos, por debajo de $1.300 \mathrm{~m} . \mathrm{s} / \mathrm{m}$, aparecen relegados a las umbrías, aunque por encima de esa cota ocupan ya cualquier exposición. Exhiben un denso subsuelo de boj y musgos que, a partir de 1.500 m. s/M van siendo sustituidos por una cubierta de gramíneas (Deschampsia flexuosa, Festuca scoparia) con Vaccinium myrtillus; a su vez, Pinus uncinata sustituye a $P$. sylvestris en el estrato arbóreo. El límite superior del bosque está muy controlado por la acción del hombre y oscila entre 1.600 y $1.800 \mathrm{~m}$. s/M, de manera que entre los campos abandonados y los pastos de verano se extiende una franja altitudinal de unos $200 \mathrm{~m}$. ocupada por pinares.

Los restantes tipos de bosque ocupan superficies mucho menores y ninguno de ellos sobrepasa el $2 \%$ del total regional. Distinguimos los abetales, que se intercalan en el pinar por encima de $1.200 \mathrm{~m}$. s/M ocupando vallonadas con aporte lateral de agua; los hayedos, localizados en cabeceras orientadas al oeste o en la parte occidental de la región, donde el pino, favorecido por la actual gestión forestal, tiende a desplazarla; los quejigales, ocupando pequeños rodales en vertientes abrigadas próximas a los pueblos y utilizados tradicionalmente para pasto de otoño e invierno del ganado de labor.

Pastos de alta montaña.-Ocupan poco más del 10\% de la superficie regional y pueden dividirse en dos grandes grupos: Los pastos abiertos con gran proporción de suelo desnudo y las tascas sobre suelos profundos. Los primeros, en áreas afectadas por procesos erosivos muy activos, aparecen dominados por comunidades en gradines de Festuca scoparia. Los segundos, a su vez, pueden dividirse en tres categorías:

- Tascas de montaña media, con Bromus erectus, Festuca rubra, Medicago suffruticosa. Resultan de la extensión del pasto 
por el hombre a costa del bosque y predominan por debajo de 1.600-1.700 m. s/M. Orlas de enebros o Echinospartum horridum en el borde superior del bosque son testigos del tradicional uso del fuego para controlar el progreso del mismo.

- Pastos densos de gramíneas robustas (Festuca eskia, F. paniculata) instalados en laderas soleadas con pendiente acusada, preferentemente en el sector oriental de la región estudiada.

- Cervunales con Nardus stricta y variable proporción de Trifolium alpinum. Predominan en los suelos profundos del sector occidental; hacia el este se ven progresivamente relegados a las depresiones donde el flujo lateral asegura una buena regulación hídrica.

\section{Relaciones entre formas de erosión y factores ambientales}

La región estudiada ocupa una superficie total de $926,5 \mathrm{~km}^{2}$, que se reducen a $876,5 \mathrm{~km}^{2}$ si eliminamos los megarritmos calcáreos, cuya morfología, estructura y respuesta frente a los agentes erosivos es diferente del conjunto del flysch. Hemos preferido observar las formas de erosión en una unidad litológica y, por ello, no se harán apenas alusiones a estos afloramientos calizos. En el mapa, para no incluir un factor más de dispersión, no se han establecido diferencias litológicas que, en su caso, se aclararán en el texto.

4.1. Métodos. Para estudiar las relaciones entre formas de erosión y factores topográficos o de uso del suelo, hemos realizado un análisis cartográfico que ha comportado las siguientes operaciones.

1.-Confección de un mapa de vegetación y uso del suelo a escala $1 / 50.000$, superponible al geomorfológico.

2.-División de la región en cuadrículas de $500 \mathrm{~m}$. de lado $(1 \mathrm{~cm}$. en el mapa $1 / 50.000$ ).

3.-Para cada cuadrícula, recogida de información topográfica: altitud del punto central, pendiente y exposición predominantes.

4.-También para cada cuadrícula, recogida de información geomorfológica y de uso del suelo. A fin de adaptarnos al grano más fino con que se habían representado ambos mapas, se registró la presencia o ausencia de cada categoría cartográfica en cada uno de los cuadrados de $250 \mathrm{~m}$. de lado que resultaron de dividir por 
cuatro las cuadrículas originales.

5.-Organización de un sistema de almacenamiento y tratamiento automático de esta información.

6.-Evaluación de las superficies totales ocupadas por las distintas clases de altitudes, pendientes, exposiciones, usos del suelo y categorías geomorfológicas.

7.-Distribución de cada forma de erosión en las distintas categorías de factores topográficos y de uso del suelo, expresada en porcentajes de ocurrencia respecto al total de cuadros en la categoría considerada. La asociación entre la presencia en cada forma de erosión y las clases del factor considerado se examinó mediante una prueba de $G$ (SOKAL .y ROHLF, 1969) practicada sobre la tabla de contigencia correspondiente. A cada subcuadrícula de $250 \mathrm{~m}$. de lado se asignaron los valores topográficos medidos en la cuadrícula original de $500 \mathrm{~m}$.

Las cuadrículas cartografiadas en el mapa de usos del suelo se fusionaron en las siguientes:

- Bosque

- Matorral y matorral arbolado

- Yermos y cultivos abandonados.

- Repoblados forestales recientes (posteriores a 1955)

- Cultivos actuales

- Pasto supraforestal xerófito (Festuca scoparia)

- Pasto supraforestal mesófito (Bromus erectus, Trifolium alpinum, Festuca eskia)

- Pasto supraforestal higrófito (Nardus stricta)

8.-Distribución de cada forma de erosión en categorías que representan combinaciones de los tres factores topográficos divididos en las siguientes clases:

Altitud: $600-1.000 \mathrm{~m} . ; 1.001-1.500 \mathrm{~m}$.; más de $1.500 \mathrm{~m}$.

Pendiente: 1lano; menos del 30\%, entre el 30 y el $50 \%$; más del $50 \%$.

Exposición: N-NE-E; SE-S-SW; W-NW.

Se utilizó también la prueba $G$ para examinar la asociación de las formas de erosión con las categorías topográficas resultantes de las combinaciones mencionadas.

A la hora de interpretar los resultados debe tenerse presente la relativa imprecisión derivada de asignar valores topográficos constan- 
tes a toda la superficie incluida en cuadrículas de $25 \mathrm{Has}(500 \mathrm{~m}$. de lado). Esta circunstancia, unida a la imprecisión de la cartografía topográfica original, afecta especialmente a las pendientes, cuyos valores deben considerarse sólo como relativos.

4.2. Caracteristicas cuantitativas del relieve. La banda altitudinal que mayor superficie ocupa es la que va de 900 a $1.200 \mathrm{~m}$. y especialmente el intervalo $1.000-1.100 \mathrm{~m}$. La figura 2 muestra que la representación es mínima por debajo de la cota 800 y por encima de la 2.000. En total, un $15,27 \%$ de la superficie se halla por encima de $1.600 \mathrm{~m}$., altitud a partir de la cual cambian buena parte de los sistemas morfoclimáticos.

Se aprecia un predominio de las exposiciones meridionales (figura 4), sobre todo al SW, muy por encima de las demás $(23,6 \%$ de la región). La orientación $\mathrm{N}$ es la menos representada $(4,6 \%)$.

En cuanto a las pendientes, se observa una marcada concentración de superficies en torno al 30-50\% (figura 3). E1 territorio con pendientes menores del $20 \%$ representa sólo un $3,45 \%$ del total. De igual forma, disminuye mucho la superficie ocupada por pendientes superiores al $60 \%\left(\right.$ sólo $58 \mathrm{~km}^{2}$ ).

Los valores de pendiente no varían libremente, sino que muestran cierto tipo de relación con la altitud y la exposición. Respecto a la primera (figura 6) vemos cómo la pendiente aumenta al progresar en altitud. En los extremos de la curva la variabilidad es mayor, debida a la escasez de puntos en el extremo superior y a la coexistencia de amplios lechos fluviales y laderas empinadas en las cotas bajas. Con todo, la variación es significativa y la curva exhibe dos rupturas o zonas donde la pendiente apenas varía con la altitud. Estas zonas se localizan alrededor de las cotas 1.100 y 1.800 y podrían expresar la huella en el relieve actual de formas maduras correspondientes a ciclos erosivos antiguos, cuya confirmación exige, sin embargo, un estudio cuantitativo más detallado.

Respecto a la variación de la pendiente con la exposición, el examen de la figura 5 pone de manifiesto una fuerte disimetría a lo largo del eje NE-SW. Las exposiciones de componente N-W, especialmente la última, muestran pendientes más elevadas que las de componente S-E. Esta coincidencia con el gradiente climático general NW-SE sugiere la influencia de la lluvia, nieve y hielo durante el Cuaternario sobre la evolución acelerada de las vertientes expuestas al flujo del Atlántico. 
4.3. Distribución geográfica de las formas de erosión. Al estimar la superficie ocupada por cada forma de relieve y de erosión a partir del mapa geomorfológico, descubrimos que la mayor parte del flysch entra dentro de dos categorías:

- En primer lugar, lo que llamamos áreas dominadas por movimientos en masa de escasa entidad y con erosión moderada (35,5\% del total).

- En segundo lugar, las laderas con arroyamiento difuso y rills temporales, que ocupan un $28,2 \%$ del territorio estudiado.

El resto, que generalmente corresponde a formas más concretas, cuenta con mucha menos superficie. Destacan ligeramente las cuencas de recepción activas $(5,6 \%)$, por encima de los frentes de cuesta $y$ escarpes de roca dura $(2,8 \%)$, las vertientes regularizadas $(2,7 \%)$ y los cursos fluviales inestables, con cauces anastomosados $(2,6 \%)$.

Otras formas, significativas por su interés morfoclimático (rigolas, conos de deyección, solifluxión y rellanos antiguos) representan superficies aún menores.

En conclusión, hallamos en el flysch extensas áreas sometidas a procesos lentos de erosión y evolución de vertientes y otras superficies, también extensas, en las que los procesos erosivos resultan de la interacción entre escorrentía y movimientos en masa muy superficiales, produciendo formas de escorrentía y arroyamiento cambiantes y poco difinidos. En el resto la dinámica de laderas responde a mecanismos muy puntuales (grandes aarranques, solifluxión) y perfectamente identificables.

Es importante también señalär que la distribución de formas de relieve y erosión es distinta en el flysch y en los relieves calizos intercalados en el flysch. Así, en estos últimos ocupan mucha menos superficie las vertientes con erosión moderada y, por el contrario, se extienden más las laderas con arroyamiento difuso; a su vez, los frentes de cuesta pasan a ser una de las formas dominantes y casi desaparecen los rellanos colgados, las vertientes regularizadas, los grandes arranques y la solifluxión.

El análisis cartográfico detallado permite comprobar que la distribución de las formas de erosión no es aleatoria, sino que muestra cierto grado de asociación con factores topográficos y de uso del suelo. Estos factores condicionan o determinan la cantidad de agua disponible y la forma en que ese agua se distribuye y circula por la ladera, lo que a su vez es responsable de los procesos de evolución de 

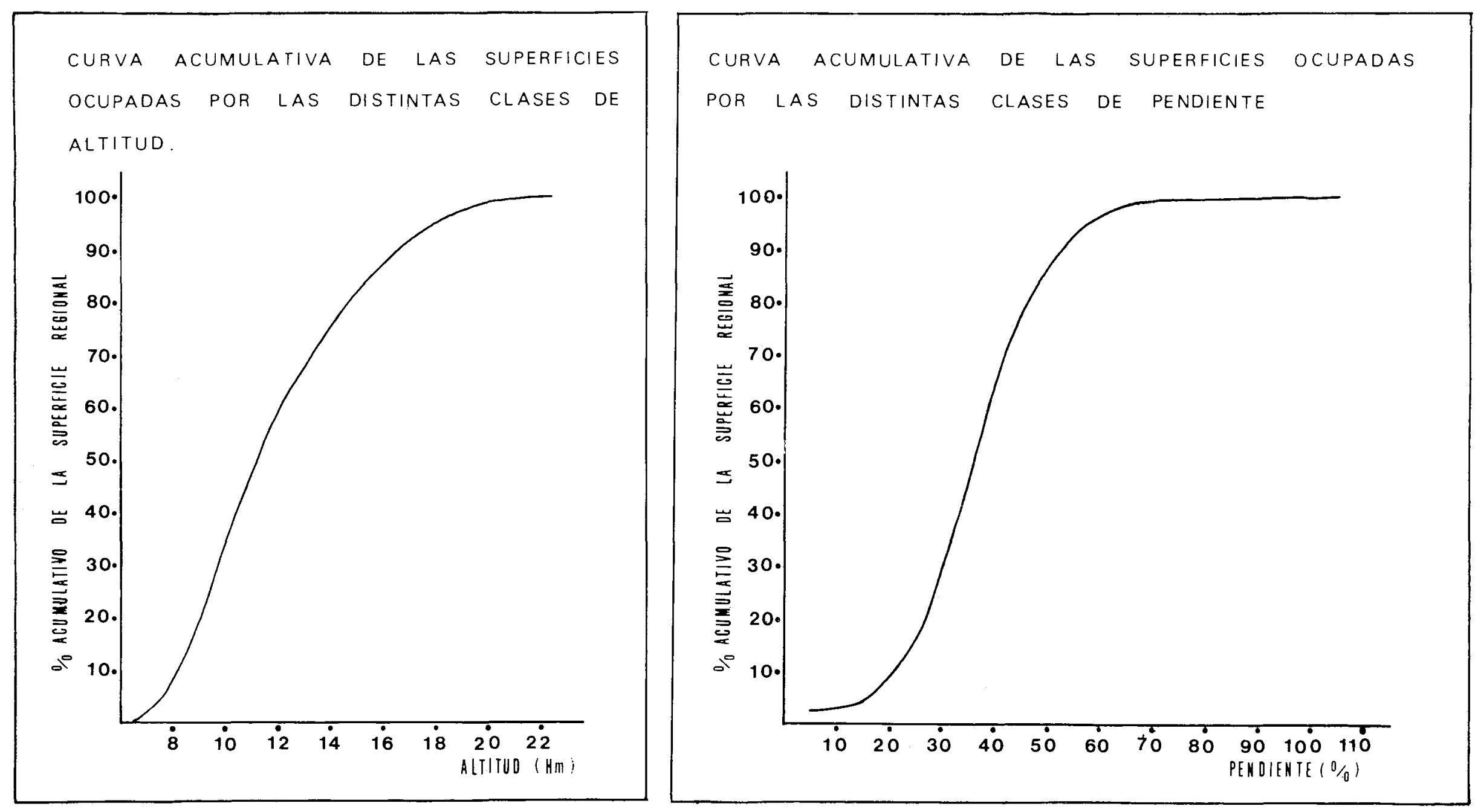

FIG. 2

FIG. 3 
PORCENTAJE DE LA SUPERFICIE REgIONAL OCUPADA POR LAS DISTINTAS EXPOSICIONES.

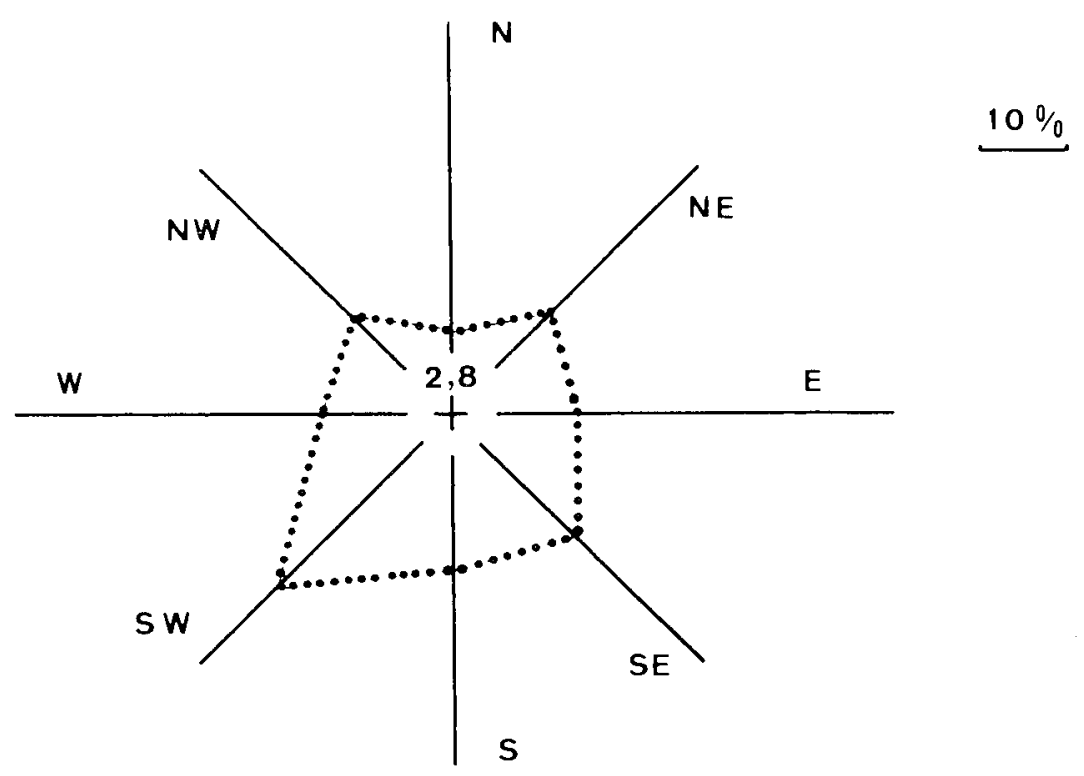

FIG. 4

DISTRIBUCION DE LOS VALORES MEDIOS DE PENDIENTE SEGUN LA EXPOSICION CON INDICACION DE INTERVALOS DE CONFIANZA DEFINIDOS POR EL ERROR TIPICO.

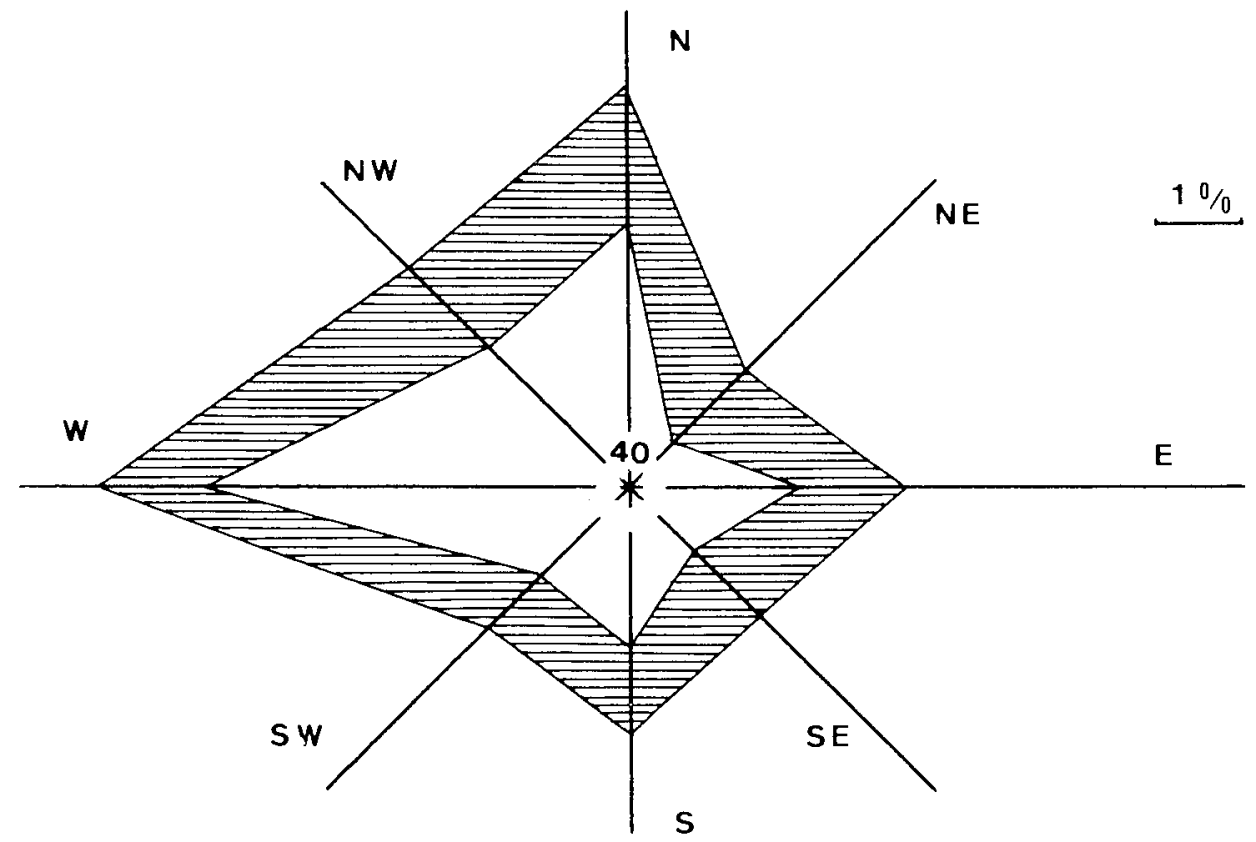

FIG. 5 
VARIACION DE LOS VALORES MEDIOS DE PENDIENTE SEGUN LA ALTITUD CON INDICACION DE INTERVALOS DE CONFIANZA DEFINIDOS POR EL ERROR TIPICO.

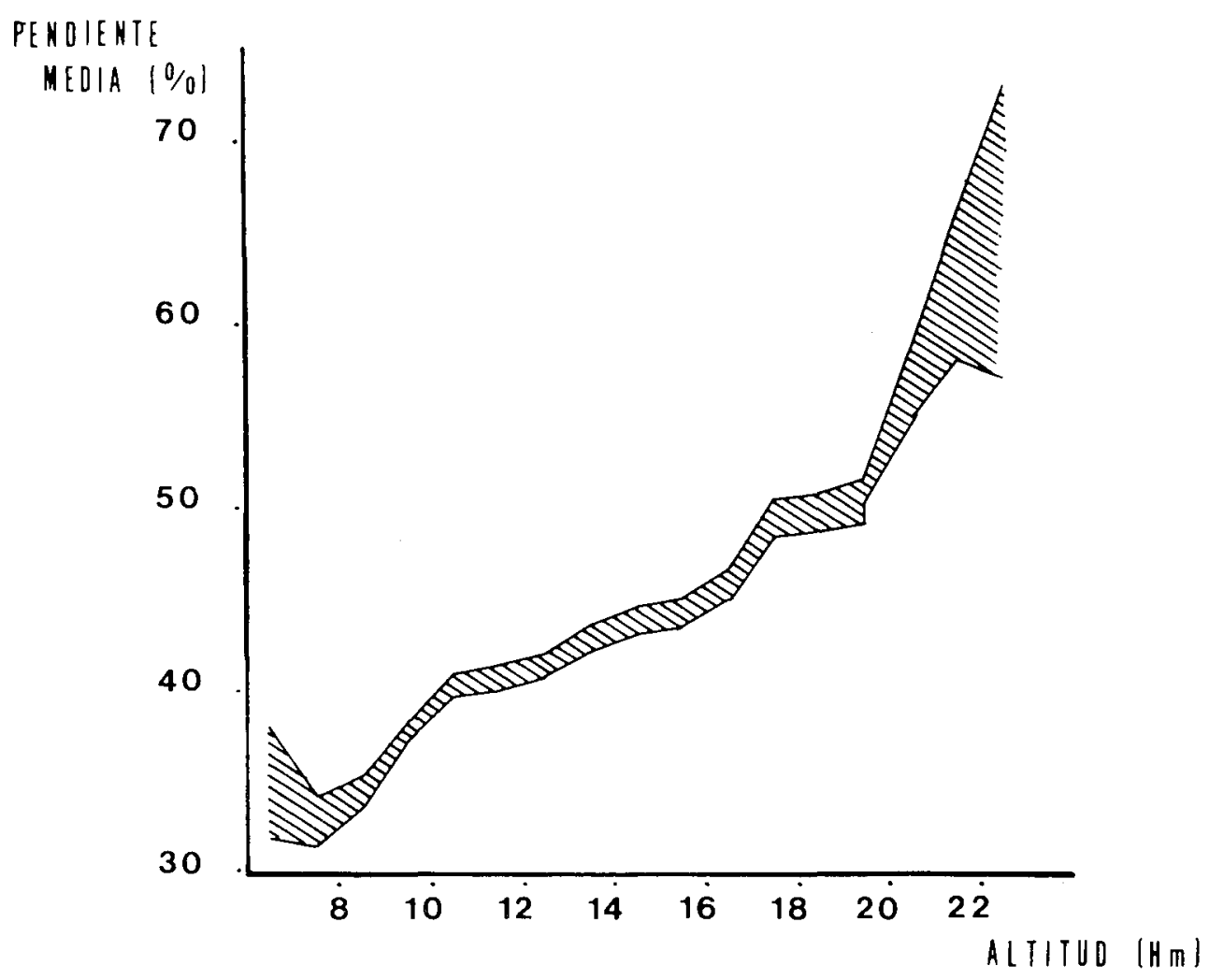

FIG. 6 
vertientes.

De todos los factores estudiados los más determinantes son la altitud y el uso del suelo, quedando en un plano algo más secundario la pendiente y, sobre todo, la exposición. El papel decisivo de los primeros no deja de ser lógico si se tiene en cuenta la diversificación de los sistemas morfoclimáticos - asociados a formas específicascon la altitud, y la acción acelerada o de freno de los cambios de vegetación frente a los procesos erosivos.

Así, por lo que respecta a la altitud se observa un claro escalonamiento de formas desde la base del flysch $(600-700 \mathrm{~m}$.) hasta las divisorias más elevadas (2.200-2.300 m.). Hasta $1.200 \mathrm{~m}$. las vertientes aparecen dominadas por arroyamiento difuso y rigolas de montaña media. A partir de $\cdot 1.100-1.200 \mathrm{~m}$. comienzan a aumentar las vertientes con erosión moderada y movimientos en masa de escasa entidad y, hasta $1.500 \mathrm{~m}$., aparecen frecuentes desprendimientos. Entre 1.300 y $1.800 \mathrm{~m}$, se conservan excelentes y extensos ejemplos de vertientes regularizadas y, finalmente, por encima de 1.600 $1.700 \mathrm{~m}$. las laderas evolucionan por solifluxión -donde el suelo es profundo-, rigolas de alta montaña y cuencas de recepción activas.

A la hora de realizar los análisis cuantitativos, la categoría geomorfológica cartografiada como rigolas se ha dividido en dos según se den por encima o por debajo de $1.500 \mathrm{~m}$. de altitud. Tal decisión se tomó al comprobar que su distribución altitudinal (tabla 2), con dos máximos a $1.000 \mathrm{~m}$. y a $1.800 \mathrm{~m}$., separados por un hiato, corrobora la impresión obtenida en el campo de que se trata de dos formas distintas, tanto por su morfología como por su génesis. 
FORMAS DE EROSION EN EL FLYSCH EOCENO SURPIRENAICO

TABLA 1

SUPERFICIE OCUPADA POR LAS DIFERENTES FORMAS

\begin{tabular}{|c|c|c|c|c|c|c|}
\hline \multirow[b]{2}{*}{ CLASE } & \multicolumn{2}{|c|}{ FLYSCH } & \multicolumn{2}{|c|}{$\begin{array}{l}\text { MEGARRITMOS } \\
\text { CALCAREOS }\end{array}$} & \multicolumn{2}{|c|}{ TOTAL } \\
\hline & $\mathrm{Km}^{2}$ & $\%$ & $\mathrm{Km}^{2}$ & $\%$ & $\mathrm{Km}^{2}$ & $\%$ \\
\hline $\begin{array}{l}\text { 1. Areas dominadas por } \\
\text { movim. en masa de escasa } \\
\text { entidad (erosión moderada) }\end{array}$ & 301,0 & 35,5 & 9,5 & 18,9 & 310,2 & 34,6 \\
\hline $\begin{array}{l}\text { 2. Laderas con arroyamiento } \\
\text { difuso y pequeñas incisiones } \\
\text { (erosión severa) }\end{array}$ & 238,6 & 28,2 & 16,1 & 32,3 & 254,7 & 28,4 \\
\hline $\begin{array}{l}\text { 3. Vertientes desnudas, sin red } \\
\text { jerarquizada, con gran erosión } \\
\text { laminar (erosión muiuy severa) }\end{array}$ & 12,1 & 1,4 & 2,3 & 4,5 & 14,4 & 1,6 \\
\hline 4. Cuencas de recepción activas & 47,2 & 5,6 & 1,4 & 2,9 & 48,6 & 5,4 \\
\hline 5. Rigolas & 19,6 & 2,3 & 0,9 & 1,8 & 20,5 & 2,3 \\
\hline 6. Solifluxión & 9,3 & 1,1 & 0,5 & 1 & 9,8 & 1,1 \\
\hline 7. Desprendimientos & 21,2 & 2,5 & 0,4 & 0,8 & 21,6 & 2,4 \\
\hline 8. Vertientes regularizadas & 22,9 & 2,7 & 0,3 & 0,5 & 23,2 & 2,6 \\
\hline 9. Rellanos colgados & 20,4 & 2,4 & 0,3 & 0,5 & 20,7 & 2,3 \\
\hline 10. Valles "en cuchara" & 11,9 & 1,4 & 0,2 & 0,4 & 12,1 & 1,4 \\
\hline $\begin{array}{l}\text { 11. Conos de deyección } \\
\text { funcionales }\end{array}$ & 4,6 & 0,6 & - & - & 4,6 & 0,5 \\
\hline $\begin{array}{l}\text { 12. Conos de deyección } \\
\text { no funcionales }\end{array}$ & 11,9 & 1,4 & - & - & 11,9 & 1,3 \\
\hline $\begin{array}{l}\text { 13. Cursos fluviales inestables } \\
\text { (anastomosados) }\end{array}$ & 21,7 & 2,6 & 0,6 & 1,1 & 22,3 & 2,5 \\
\hline $\begin{array}{l}\text { 14. Rellanos de obturación } \\
\text { glaciar }\end{array}$ & 8,8 & 1,1 & - & - & 8,8 & 1,0 \\
\hline $\begin{array}{l}\text { 15. Frentes de cuesta y escarpes } \\
\text { en roca viva }\end{array}$ & 23,6 & 2,8 & 14,8 & 29,6 & 38,4 & 4,3 \\
\hline 16. Morrenas & 19,9 & 2,4 & - & - & 19,9 & 2,2 \\
\hline 17. Terrazas fluviales & 14,7 & 1,7 & 0,5 & 1,0 & 15,2 & 1,7 \\
\hline
\end{tabular}


TABLA 2

\section{INFLUENCIA DE LOS FACTORES AMBIENTALES EN LAS FORMAS DE EROSION}

Porcentaje de las formas de erosión sobre la superficie ocupada por cada categoría de los factores considerados. La asociación es significativa para un nivel del $99,5 \%$ excepto en los casos señalados con N.S. (*: valor inferior al $1 \%$ ).

ALTITUD (en metros)

\begin{tabular}{lcccrrrrr} 
& $600 / 700$ & $700 / 800$ & $800 / 900$ & $900 / 1000$ & $1000 / 1100$ & $1100 / 1200$ & $1200 / 1300$ & $1300 / 1400$ \\
\hline Arroyamiento difuso & 29,2 & 42,3 & 41,4 & 39,3 & 44,3 & 37,1 & 27,2 & 16,8 \\
Rills montaña media & 3,3 & 1,4 & $*$ & 2,8 & 2,1 & 2,2 & 1,0 & $*$ \\
Erosión moderada & 5,6 & 11,3 & 15,7 & 24,7 & 29,1 & 36,9 & 43,4 & 49,6 \\
Desprendimientos & 0 & 1,2 & $*$ & 1,3 & 1,5 & 3,1 & 5,6 & 6,7 \\
Cabeceras activas & 0 & $*$ & $*$ & 1,5 & 1,9 & 2,3 & 2,3 & 4,0 \\
Rills alta montaña & 0 & 0 & 0 & 0 & 0 & 0 & 0 & 0 \\
Solifluxión & 0 & 0 & 0 & 0 & $*$ & 0 & $*$ & 0 \\
Vertientes regulariz. & 2,2 & 1,6 & 1,7 & $*$ & 1,0 & 1,0 & 2,8 & 7,1
\end{tabular}

\section{ALTITUD (en metros)}

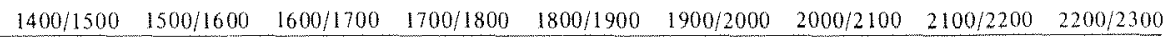

\begin{tabular}{lccccccccc}
\hline Arroyamiento difuso & 14,3 & 9,7 & 3,8 & 3,7 & 3,5 & 2,1 & 2,1 & 2,8 & 0 \\
Rills montaña media & $*$ & 0 & 0 & 0 & 0 & 0 & 0 & 0 \\
Erosion moderadia & 53,5 & 58,8 & 48,1 & 42,0 & 36,0 & 25,8 & 34,0 & 22,8 \\
Desprendimientos & 3,0 & 2,0 & 1,1 & $*$ & $*$ & 0 & 0 & 0 & 0 \\
Cabeceras activas & 6,4 & 7,8 & 11,7 & 20,7 & 29,1 & 29,8 & 35,5 & 25,7 & 4,0 \\
Rills alta montaña & 0 & 2,0 & 4,6 & 4,7 & 4,2 & 9,9 & 5,0 & 1,0 & 0 \\
Solifluxión & $*$ & 1,2 & 7,0 & 5,3 & 6,7 & 11,3 & 3,6 & 2,8 & 0 \\
Vertientes regulariz. & 7,0 & 6,9 & 7,7 & 4,3 & 2,2 & 3,2 & 1,4 & 12,8 & 0
\end{tabular}

PENDIENTE (en \%)

\begin{tabular}{|c|c|c|c|c|c|c|c|c|c|}
\hline & Llano & $10-20$ & $20-30$ & $30-40$ & $40-50$ & $50-60$ & $60-70$ & $70-80$ & $80-90$ \\
\hline Erosión moderada & 6,7 & 13,7 & 27,8 & 33,1 & 39,2 & 43,1 & 39,3 & 37,5 & 33,9 \\
\hline Cabeceras activas & 0 & 0 & 1,3 & 3,2 & 5,5 & 12,2 & 11,0 & 14,1 & 13,2 \\
\hline Rills alta montaña & 0 & 0 & $*$ & $*$ & 1,1 & 1,3 & 3,2 & 2,5 & 1,8 \\
\hline
\end{tabular}

EXPOSICION

\begin{tabular}{lllrrrrrrrr} 
& Llano & \multicolumn{1}{c}{$\mathrm{N}$} & $\mathrm{NL}$ & \multicolumn{1}{c}{$\mathrm{L}$} & \multicolumn{1}{c}{$\mathrm{SE}$} & \multicolumn{1}{c}{$\mathrm{S}$} & $\mathrm{SW}$ & $\mathrm{W}$ & NW \\
\hline Arroyamiento difuso & 2,0 & 15,2 & 22,1 & 26,6 & 33,6 & 38,8 & 34,5 & 25,4 & 17,4 \\
Rills montaña media & 0 & 0 & 1,4 & 1,2 & 1,5 & 1,2 & 1,8 & 1,0 & 1,4 \\
Erosióm moderada & 6,7 & 52,6 & 41,3 & 34,9 & 31,6 & 30,9 & 32,9 & 41,7 & 41,0 \\
Desprendimientos & 0 & 1,1 & 2,3 & 2,4 & 3,2 & 2,3 & 3,1 & 1,9 & 2,3 \\
Cabeceras activas & 0 & 8,2 & 4,9 & 6,1 & 5,1 & 6,2 & 5,1 & 4,4 & 7,7 \\
Rills alta montaña & 0 & $*$ & 2,4 & 1,5 & $*$ & $*$ & $*$ & $*$ & 2,6 \\
Solifluxión & 0 & $*$ & $*$ & 1,1 & 1,2 & 1,3 & 1,3 & $*$ & 1,2 & N.S. \\
Vertientes regulariz. & 0 & 5,3 & 4,7 & $*$ & 1,8 & 2,5 & 3,9 & 2,3 & 5,0
\end{tabular}

VEGETACION

\begin{tabular}{lcccccccc} 
& $\begin{array}{c}\text { Bosque } \\
\text { cerrado }\end{array}$ & $\begin{array}{c}\text { Bosque claro } \\
\mathrm{y} \text { matoral }\end{array}$ & $\begin{array}{c}\text { Pasto } \\
\text { hidrófito }\end{array}$ & $\begin{array}{c}\text { Pasto } \\
\text { mesófito }\end{array}$ & $\begin{array}{c}\text { Pasto } \\
\text { xerófito }\end{array}$ & $\begin{array}{r}\text { Cultivos } \\
\text { actuales }\end{array}$ & $\begin{array}{c}\text { Cultivos abandonados } \\
\text { Repoblac. }\end{array}$ \\
\hline Arroyamiento difuso & 1,2 & 4,3 & 0 & 4,1 & 2,4 & 8,3 & 58,8 & 37,7 \\
Rill montaña media & $*$ & 1,9 & 0 & 0 & $*$ & $*$ & 1,4 & 3,7 \\
Erosión moderada & 61,0 & 25,4 & 56,3 & 48,3 & 24,6 & 15,6 & 16,0 & 26,3 \\
Desprendimientos & 1,4 & 3,7 & 0 & $*$ & $*$ & $*$ & 1,4 & 9,3 \\
Cabeceras activas & 3,3 & 5,4 & 1,0 & 13,4 & 30,9 & $*$ & 1,6 & 4,4 \\
Rills alta montaña & $*$ & $*$ & 4,5 & 2,4 & 9,6 & 0 & 0 & 0 \\
Solifluxión & $*$ & $*$ & 2,7 & 14,8 & 2,8 & 0 & 0 & $*$ \\
Vertientes regulariz: & 6,1 & 1,7 & 0 & 5,5 & $*$ & $*$ & 1,5 & 1,3
\end{tabular}


La influencia de la vegetación presenta unas características similares a las anteriores, cosa explicable pues en su distribución el factor altitud es decisivo. Así, el arroyamiento difuso se halla asociado a campos abandonados, bosque abierto, matorral y áreas de repoblación forestal; los grandes desprendimientos se localizan sobre todo en repoblados y, en menor medida, en bosque abierto y matorral; las vertientes regularizadas se conservan bien en laderas con bosque cerrado y pasto mesófito, que son también áreas donde la erosión es moderada; la solifluxión aparece sobre pasto mesófito y las rigolas de alta montaña sobre pasto xerófito, como asimismo las cuencas de recepción activas.

La pendiente contribuye a matizar mejor la distribución de las formas de erosión, aunque de los cálculos realizados se desprenden algunas aparentes sorpresas que serán explicadas más adelante. Así, pendientes relativamente bajas soportan erosiones intensas por arroyamiento difuso, rigolas temporales, incisiones, etc., mientras lo que llamamos vertientes con erosión moderada encuentran su óptimo conforme aumenta la pendiente. Dejando a un lado esta anomalía, los procesos erosivos tienden a ser más activos con pendientes elevadas; así sucede con las cabeceras activas de torrentes o con los rills de alta montaña, mientras la solifluxión suele ser bastante indiferente a la pendiente con tal de que ésta supere el $20 \%$.

Por último, la exposición de las vertientes parece tener una influencia menos decisiva, aunque sin duda es importante y, más aún, en la aparición o no de determinados procesos de detalle. Los resultados obtenidos permiten afirmar que las vertientes que miran al $\mathrm{N}$, NW y NE son las más proclives a las vertientes regularizadas, las rigolas de alta montaña y a la existencia de laderas con erosión nula o moderada; las cabeceras activas, aunque de forma más indiferente, también presentan alguna preferencia por orientaciones septentrionales ( $\mathrm{N}$ y NW). Por el contrario, las vertientes meridionales soportan con mayor intensidad grandes desprendimientos y arroyamiento difuso.

El estudio de la asociación de cada forma de erosión con las combinaciones de los factores topográficos (vid. métodos) permite obtener información adicional y más global acerca de los factores de distribución de tales formas.

Así, las vertientes controladas por el arroyamiento difuso muestran una localización preferente por debajo de $1.000 \mathrm{~m}$., en laderas 
solanas y con pendiente inferior al $50 \%$, aunque también se hallan muy desarrolladas en pendientes de más del $50 \%{ }^{1}$. Dichas laderas se encuentran ocupadas en su mayor parte por cultivos abandonados, bosque abierto y matorral. En exposiciones $\mathrm{N}$ la superficie ocupada por este tipo de procesos disminuye sensiblemente y también lo hace al aumentar la altitud, de forma que a partir de $1.600 \mathrm{~m}$. deja de tener importancia. De igual forma, el arroyamiento difuso es mínimo bajo el bosque cerrado o en laderas con cultivos actuales. Se trata, pues, de una distribución muy relacionada con territorios alterados por acciones antrópicas.

En efecto, la aparición de arroyamien to difuso, rills temporales, áreas de arranques y pequeñas incisiones, con eliminación de más del $50 \%$ de la cobertera edáfica, requiere una vegetación aclarada y más aún campos abandonados en estado sucesional incipiente para que se dé importante escorrentía superficial. Tales campos abandonados -como los repoblados y matorral- dominan la mayoría de las laderas bajas en exposición solana, con pendientes a veces muy fuertes (ANGLADA et al, 1980). Y las mismas razones justifican la distribución similar de los rills de montaña media, ligados a laderas repobladas y abandonadas a altitudes inferiores a $1.200 \mathrm{~m}$.

Las áreas con erosión moderada presentan una distribución más compleja. Su importancia aumenta progresivamente con la altitud hasta $\operatorname{los} 1.600 \mathrm{~m}$., momento a partir del cual se produce una disminución; asimismo, también aumenta conforme lo hace la pendiente, hasta el umbral del $70 \%$; tienen una clara preferencia por las vertientes septentrionales excepto a partir de $1.500 \mathrm{~m}$. En resumen, diríamos que este tipo de vertientes hallan su óptimo por encima de $1.000 \mathrm{~m}$. de altitud, en vertientes $\mathrm{NW}, \mathrm{N}$ o $\mathrm{NE}$, con pendientes superiores al $50 \%$ y con una vegetación de bosque cerrado o con pastos hidrófilos y mesófilos. No tiene apenas representación por debajo de $1.000 \mathrm{~m}$., en laderas solanas y con pendiente inferior al $30 \% \mathrm{y}$, desde luego, se da muy poco en áreas con campos abandonados.

Esta distribución se justifica en parte por razones opuestas a las señaladas para el arroyamiento difuso. La erosión es menor al encontrar territorios más elevados porque en ellos hay menos deterioro

1. El $57 \%$ de las laderas entre 600 y $1.000 \mathrm{~m}$., con exposición $\mathrm{S}$ y pendiente entre $30 \mathrm{y}$ $50 \%$ está sometido a arroyamiento difuso. 
DISTRIBUCION DE FORMAS DE EROSION SEGUN COMBINACIONES DE FACTORES TOPOGRAFICOS EN ZONAS DE FLYSCH

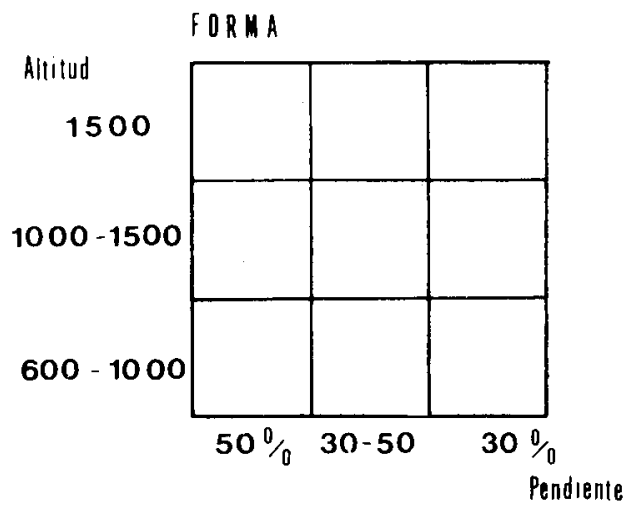

ORIENTACIONES

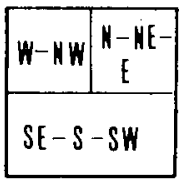

Erosion laminar serera

Grandes arranques

\begin{tabular}{|c|c|c|c|c|c|}
\hline 10 & 9 & 9 & 4 & & \\
\hline \multicolumn{2}{|c|}{8} & \multicolumn{2}{|c|}{4} & \multicolumn{2}{|c|}{7} \\
\hline & & & & & \\
\hline 1 & & & & \\
\hline & & & & & \\
\hline & & & & & \\
\hline
\end{tabular}

\begin{tabular}{|c|c|c|c|c|c|}
\hline$*$ & $*$ & $*$ & $*$ & & \multicolumn{2}{|c|}{} \\
\hline \multicolumn{2}{|c|}{} & \multicolumn{2}{|c|}{1} & \multicolumn{2}{|c|}{} \\
\hline 2 & $*$ & 4 & 4 & 3 & 2 \\
\hline 1 & \multicolumn{2}{|c|}{5} & \multicolumn{2}{|c|}{3} \\
\hline$*$ & $*$ & 2 & $*$ & & $*$ \\
\hline 2 & \multicolumn{2}{|c|}{1} & \multicolumn{2}{|c|}{$*$} \\
\hline
\end{tabular}

Arroyamiento difuso

\begin{tabular}{|c|c|c|c|c|c|}
\hline$*$ & 3 & 3 & 6 & $*$ & $*$ \\
\hline \multicolumn{2}{|c|}{5} & \multicolumn{2}{|c|}{7} & \multicolumn{2}{|c|}{9} \\
\hline 16 & 26 & 23 & 23 & 23 & 29 \\
\hline 33 & \multicolumn{2}{|c|}{38} & \multicolumn{2}{|c|}{40} \\
\hline 26 & 25 & 45 & 34 & 25 & 28 \\
\hline \multicolumn{2}{|c|}{47} & \multicolumn{2}{|c|}{57} & \multicolumn{2}{|c|}{51} \\
\hline
\end{tabular}

Rigolas

de montaña media

\begin{tabular}{|c|c|c|c|c|}
\hline 3 & $*$ & 6 & 9 & \\
\hline \multicolumn{2}{|l|}{4} & \multicolumn{2}{|c|}{8} & * \\
\hline & & & $\bullet$ & \\
\hline & & & & \\
\hline & & & & \\
\hline & & & & \\
\hline
\end{tabular}

\begin{tabular}{|c|c|c|c|c|c|}
\hline 41 & 38 & 41 & 36 & 56 & 53 \\
\hline \multicolumn{2}{|c|}{43} & \multicolumn{2}{|c|}{51} & \multicolumn{2}{|c|}{47} \\
\hline 60 & 46 & 48 & 48 & 33 & 38 \\
\hline \multicolumn{2}{|c|}{44} & \multicolumn{2}{|c|}{34} & \multicolumn{2}{|c|}{26} \\
\hline 28 & 33 & 25 & 35 & 24 & 21 \\
\hline \multicolumn{2}{|c|}{19} & \multicolumn{2}{|c|}{13} & \multicolumn{2}{|c|}{8} \\
\hline
\end{tabular}

Rigolas de alta montaña

Cueneas de recepcion activas

\begin{tabular}{|c|c|c|c|c|c|c|}
\hline 4 & & 3 & 5 & & \\
\hline \multicolumn{2}{|c|}{3} & \multicolumn{2}{|c|}{9} & \multicolumn{2}{|c|}{21} \\
\hline 3 & 2 & 4 & 5 & 10 & 5 \\
\hline 2 & \multicolumn{2}{|c|}{2} & \multicolumn{2}{|c|}{2} \\
\hline 5 & 1 & 2 & 2 & \multicolumn{2}{|c|}{} \\
\hline 1 & \multicolumn{2}{|c|}{2} & \multicolumn{2}{|c|}{} \\
\hline
\end{tabular}

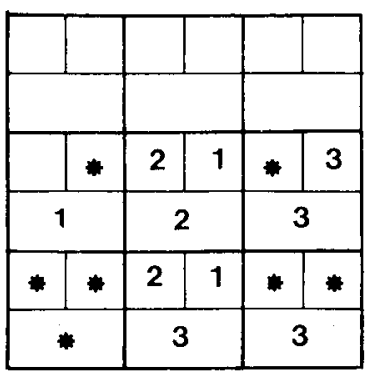

\begin{tabular}{|c|c|c|c|c|c|c|}
\hline 25 & 28 & 15 & 16 & & $*$ \\
\hline 27 & \multicolumn{2}{|c|}{12} & \multicolumn{2}{|c|}{} \\
\hline 3 & 4 & 3 & 3 & $*$ & 1 \\
\hline \multicolumn{2}{|c|}{4} & \multicolumn{2}{|c|}{3} & \multicolumn{2}{|c|}{1} \\
\hline$*$ & $*$ & 2 & 1 & $*$ & $*$ \\
\hline & $*$ & \multicolumn{2}{|c|}{2} & \multicolumn{3}{|c|}{} \\
\hline
\end{tabular}

FIG. 7 
de los sistemas naturales por acciones antrópicas, de forma que el óptimo se sitúa entre 1.300 y $1.800 \mathrm{~m}$. A su vez, la contradicción planteada por la pendiente se explica porque las laderas menos inclinadas son las que han estado sometidas de forma más intensa a cultivos itinerantes y más aún en solanas; son las laderas marginadas por el hombre -las que tienen mayores pendientes-las que soportan hoy menos erosión hasta determinado límite $(70 \%)$ a partir del cual la inestabilidad de la vertiente es suficientemente grande como para que aparezcan importantes procesos erosivos. Es interesante señalar también que por encima de $1.500 \mathrm{~m}$., donde las acciones humanas son más limitadas, las vertientes con erosión nula o moderada tienen mayor preferencia por las pendientes inferiores al $30 \%$, prueba de que el papel de la pendiente ha sido alterado por el hombre.

Los grandes desprendimientos se distribuyen, por el contrario, de forma más sencilla. Tienden a aparecer entre 1.000 y $1.500 \mathrm{~m}$., alcanzando su máximo con un $30-50 \%$ de pendiente, y con exposición solana, aunque el resto de las orientaciones cuentan con un buen número de ellos. Coinciden asimismo de manera casi exclusiva con áreas de repoblación forestal porque ésta se realizó en áreas proclives a los grandes movimientos en masa, y, algo menos, en bosque abierto y matorral. Por encima de $1.500 \mathrm{~m}$. este tipo de evolución de vertientes carece de significación. Igualmente se reduce su frecuencia en pendientes inferiores al 30\% y superiores al 50\%. En estas últimas porque coinciden con rocas más resistentes ${ }^{2}$-mayor presencia de areniscas - y porque disponen de una más densa cobertera vegetal. Sin duda la eliminación de la vegetación original ha sido un factor de aceleración.

Por su parte, la solifluxión y deslizamientos superficiales sólo tienen lugar por encima de $1.500 \mathrm{~m}$. de altitud. En este caso los resultados obtenidos respecto de la pendiente y exposición no son tan significativos; sí lo son en cambio los referidos a vegetación, pues tales procesos aparecen muy ligados a los pastos mesófitos y mucho menos a los xerófitos ${ }^{3}$. Son, pues, ambientes supraforestales, con suelo profundo susceptible de deslizarse ladera abajo. Por debajo del nivel superior del bosque el suelo también se des-

2. No olvidemos que estos desprendimientos afectan también al sustrato.

3. E1 $14 \%$ de la superficie ocupada por pastos mesófitos está sometido a solifluxión y deslizamientos en la actualidad. En tales territorios son aún mucho más frecuentes los lóbulos de solifluxión fósiles. 
plaza -reptación- pero lo hace de forma más lenta y sin que se lleguen a formar cicatrices.

Las cuencas de recepción activas son menos específicas de la alta montaña que la solifluxión, aunque la mayor densidad se alcanza por encima de $1.500 \mathrm{~m}$. de altitud, con pendiente superior al $50 \% \mathrm{y}$, sobre todo, en torno al 70-90\%, con pasto Xerófito o incluso con la roca al desnudo por la propia acción erosiva de la cabecera. El papel de la pendiente como factor de aceleración es evidente en este sentido. La exposición no parece ser un factor determinante, aunque las vertientes que miran al N, NW y NE son las más afectadas por este tipo de formas.

Más limitadas a la alta montaña aunque en relación con las cuencas de recepción activas, las vertientes desnudas sin red jerarquizada encuentran su máxima expansión por encima de $1.600 \mathrm{~m}$., con pendiente superior al $50 \%$ y exposición umbría.

Las rigolas de alta montaña ocupan espacios importantes entre 1.600-1.700 m., en exposiciones más bien septentrionales y con pendiente entre el 60 y 70\%, acompañados de pasto xerófito, es decir con suelo no muy profundo. En caso contrario, con esa pendiente las vertientes aparecerían dominadas por solifluxión. Esta distribución permite suponer una influencia decisiva de la fusión de la nieve.

Aunque se trata de formas fósiles, aludimos aquí a la distribución de las vertientes regularizadas. Su mejor estado de conservación parece alcanzarse entre 1.300 y $1.700 \mathrm{~m}$. en exposiciones meridionales, aunque cuando se sitúan a altitudes inferiores lo normal es que dominen las exposiciones umbrías. En las primeras se asocian a pasto mesófito $\mathrm{y}$ en las segundas al bosque cerrado. En las áreas más elevadas también se conservan vertientes de este tipo mirando al $\mathrm{N}$, aunque son mucho menos frecuentes, bien porque no se formaron en condiciones de frío muy riguroso o porque han sido desmanteladas por las cabeceras activas de torrentes. En las laderas bajas, próximas a los ríos, aparecen asimismo muchos ejemplos de vertientes regularizadas formando facetas triangulares (BARRERE, 1966), aunque numerosas de entre ellas se encuentran en pleno proceso de degradación por abarrancamiento. 


\section{Los sistemas de erosión en el flysch}

Con el fin de disponer de una perspectiva más global acerca de la dinámica de vertientes en el flysch, describimos a continuación ciertos aspectos funcionales de las distintas formas de erosión in tegrándolas en tres ambientes clásicos dentro del flysch: las vertientes supraforestales, el bosque y las áreas degradadas y de cultivos abandonados, cada uno de ellos con dinámica y problemas bien diferentes.

a) Los sistemas de erosión en vertientes supraforestales. Los ambientes situados por encima del nivel del bosque han experimentado un notable incremento superficial por razones antrópicas. Las necesidades de ampliar la superficie de pastos de verano obligaron a la roturación de extensas áreas de bosque en un momento histórico no bien ajustado aún cronológicamente. El mantenimiento de una fuerte densidad de ganado estacional ha evitado el regreso al estado de bosque, lo que ha permitido ampliar aquello que podríamos llamar "media-alta montaña", con sus secuelas morfológicas.

El espacio supraforestal presenta una gran complejidad porque incorpora muy diferentes ambientes topográficos y climáticos. En términos generales se caracteriza por la existencia de divisorias suaves a una altura relativamente constante, a veces relacionadas con frentes de cuesta de escasa entidad, tanto más frecuentes cuanto más al N. Desde la divisoria hasta el nivel del bosque las vertientes aparecen unas veces regularizadas y otras con perfiles complejos en los que con frecuencia se adivinan pequeñas hombreras. Antiguos fondos glaciares se encuentran ocasionalmente al pio de estas vertientes, con formas suaves y abiertas, tapizadas por pastos higrófilos (Plandániz y Diostesalve, en el valle de Hecho). Lo normal, sin embargo, es que las laderas supraforestales pasen sin solución de continuidad al nivel de bosque.

La evolución actual de las vertientes se halla controlada por la presencia o no de suelo profundo, lo que a su vez está condicionado por la pendiente. En las áreas muy pendientes próximas a las divisorias la ladera aparece sin suelo, cubierta por un manto de derrubios con piedras grandes (superiores a $20 \mathrm{~cm}$.), relativamente estables, en las que hay muestras de gelifracción actual. Algunas coladas de piedras y terracillas de gelifluxión aparecen ocasionalmente, aunque lo normal es un paisaje amorfo con caos de bloques. Ello dificulta, sin duda, la incisión lineal de la escorrentía superficial, que se infiltra $\mathrm{y}$ disipa entre las piedras. 
En áreas próximas y con características muy similares se instalan cabeceras de torrentes actualmente funcionales. Poseen pendiente aún más fuerte y cuentan con abundantes piedras que se entremezclan caóticamente con pequeñas coladas entre las que se abren pequeños cauces de posición cambiante.Algunas de estas cabeceras se encuentran bien inscritas en la vertiente pero otras forman simples áreas cóncavas que denotan una menor actividad. La gran alimentación en piedras y la fuerte pendiente de los canales de desagüe permiten la existencia de aportes torrenciales en los momentos de precipitaciones máximas; de ahí la formación de pequeños pero muy activos conos de deyección cuyo cauce principal está cambiando continuamente (barranco del Puerto, en el valle del Gállego).

En situación muy próxima también a la divisoria, se localizan con frecuencia laderas con suelo no muy profundo -en algunos casos por desmantelamiento- y a veces incluso muy pedregoso, sometidas a un drenaje muy denso. Son antiguas vertientes regularizadas, con fuerte pendiente $(60-70 \%)$, ocupadas por una densa red de rigolas (rills) rectilíneas que no llegan a integrarse en cauces de orden superior. Se trata de canales no encajados y paralelos entre los que se muestran divisorias suaves, restos de la vertiente regularizada. Su equilibrio con las condiciones climáticas actuales es dudoso y, en algún caso (cabecera de Lubierre), es evidente que son subactuales: presencia de pinos jóvenes en los cauces y ruptura de pendiente al enlazar con la red fluvial general. Algunas laderas de este tipo parecen evolucionar más por micro-rigolas (Las Blancas) que se destruyen periódicamente por el avance y cambio de posición de terracillas de gelifluxión, que impiden así la formación de nuevas y auténticas rigolas.

Estas vertientes plantean numerosos problemas (aparte de su funcionalidad actual) relacionados con su origen y evolución. Desconocemos asimismo, cuáles son las condiciones hídricas bajo las que se inscriben, aunque por la altitud y orientación dominantes cabe pensar en un papel importante de la nieve ${ }^{4}$. Por otra parte, los cauces se interrumpen a veces para continuar más abajo, lo que sugiere una influencia de la escorrentía subcortical ${ }^{5}$.

4. La nieve, por otra parte, al cubrir la vertiente durante gran parte del año y en especial en las épocas de mayores precipitaciones, dificulta la profundización del cauce y la integración.

5. Además, por debajo de la rigola, el suelo está más suelto y con numerosos huecos; ello indica un posible lavado de finos por parte de pipes quizás no demasiado marcados. 
Fuera de estas áreas desnudas, total o parcialmente, el flysch aparece casi siempre recubierto por un suelo profundo, de potencia variable, procedente de la alteración de areniscas y margas; posee un color pardo-amarillento. Sobre este suelo, tapizado de pasto mesófito, actuó la solifluxión hasta épocas relativamente recientes $^{6}$, lo que ha dotado a las vertientes de una morfología suavemente ondulada en la que se distinguen con claridad los antiguos lóbulos. Asimismo, la solifluxión es responsable de que el espesor del suelo no sea homogéneo, al dar lugar a acumulaciones mayores en unos puntos que en otros, y de que el drenaje esté muy poco organizado. En la actualidad, los lọbulos no parecen funcionales, al menos a escala hectométrica, pues no se aprecian frentes corrugados, aunque la presencia de microterracillas indica que la estabilidad no es completa.

En estos ambientes con suelo profundo, las condiciones de infiltración del agua de lluvia y de fusión de la nieve están controladas por:

- el incremento de arcilla en profundidad; el agua tiende a circular inmediatamente por encima del nivel más arcilloso;

- la existencia de numerosas toperas que dirigen y organizan la circulación hídrica, drenando unas veces el exceso de agua y otras provocando la formación de áreas ocasionalmente encharcadas; parte de la tierra removida por los topillos cada invierno es arrastrada por el agua de fusión de nieve y se acumula en pequeños rellanos in termedios.

- el horizonte A, con muchas raíces, que al ser más poroso absorbe gran parte del agua de fusión, creándose así una capa superficial saturada.

Estas condiciones de infiltración originan procesos muy variados entre los que por su espectacularidad destacan los deslizamientos masivos. Afectan exclusivamente a la cobertera edáfica $-y$ a veces a su totalidad - y representan problemas similares a los descritos por GARCIA-RUIZ y ARBELLA (1981) para suelos profundos de Monte Perdido y por SOUTADE (1980) para el Pirineo Oriental.

Los deslizamientos tienen formas y dimensiones muy variadas, unas veces claramente semicirculares y otras alargadas en el sentido

6. Existen ramas quemadas englobadas dentro de los lóbulos y que suponemos pertenecen al momento de destrucción del bosque original por parte del hombre. 
de la pendiente; unas veces poco mayores de $1 \mathrm{~m}^{2}$ y otras afectando a varios cientos de $\mathrm{m}^{2}$. Ello depende en parte de las condiciones topográficas y del espesor del suelo afectado por el deslizamiento. Muchos de ellos aparecen en los frentes de antiguos lóbulos de solifluxión -allí donde se produce una ruptura de pendiente-o se hallan asociados a irregularidades del sustrato ${ }^{7}$. Forman siempre una cicatriz -en ocasiones de configuración no bien definida-, simple o compuesta por coalescencia de varios deslizamientos, y al pie suele hallarse un lóbulo que puede incluso haber sido desmantelado por las aguas de escorrentía.

Interesa señalar también que los procesos causantes de estos deslizamientos son totalmente locales, ligados al funcionamiento hídrico del suelo, pues no se hallan en relación con la red fluvial general. Algunas cicatrices se suceden en cadena y llegan a formar líneas de drenaje, pero en la mayoría de los casos no conectan con la erosión remontante procedente de la parte baja del valle; normalmente incluso poseen un drenaje difuso aguas abajo y el agua de escorrentía se disipa por entre el pasto ${ }^{8}$. En PUIGDEFABREGAS y GARCIA-RUIZ (en prensa) puede hallarse información más exhaustiva sobre las características, dinámica y posible origen de estos fenómenos.

Sobre estos suelos profundos tiene lugar también la formación de microcoladas en el borde de planchas o láminas de gelifluxión, que no son colonizadas inmediatamente por la vegetación porque lo impide la remoción del suelo provocada por los pipkrakes. Se forman así pequeños ostiolos (de $20-30 \mathrm{~cm}$. de diámetro) que al año siguiente serán fosilizados por reptación.

b) Los sistemas de erosión en el bosque. El bosque presenta una aparente mayor homogeneidad que el espacio supraforestal o las vertientes bajas degradadas. En parte es como si la cobertera forestal eliminase la diversidad configurada por la pendiente, la exposición o el espesor del suelo. Sin embargo, observaciones más detalladas permiten intuir que el bosque ofrece una gama importante de procesos funcionales, sin duda menos espectaculares que cuando no

7. Numerosas cicatrices se sitúan sobre convexidades del sustrato, allí donde el espesor de suelo es menor y donde, lógicamente, puede producirse un mayor embebimiento en agua (ver también GARCIA-RUIZ y ARBELLA, 1981).

8. No obstante, hemos podido comprobar que, cuando la pendiente es fuerte, de algunas cicatrices surgen rigolas rectilíneas, lo que explica la ausencia de cuenca de recepción, por tratarse en ese caso de un proceso de erosión progresivo y no remontante. 
existe la protección arbórea.

Las áreas ocupadas por el bosque cerrado y controladas en su morfodinámica por éste, tienden a localizarse en vertientes septentrionales entre 1.200 y $1.700 \mathrm{~m}$. de altitud. Muchas de esas laderas se encuentran regularizadas, con perfiles rectilíneos y apenas surcadas por barrancos. A veces enlazan y se prolongan directamente con las vertientes supraforestales, pero otras se inician al pie de escarpes estructurales de los que forman el talud. En el primer caso, las laderas se encuentran recubiertas por el mismo tipo de suelo antiguo y profundo en el que se aprecian formas antiguas de solifluxión. Más abajo -entre 1.400 y $1.500 \mathrm{~m}$.- aquél se adelgaza y pasa a ser un suelo más pedregoso formado por coluviones. En el segundo caso las vertientes poseen el típico talud de derrubios con piedras de tamaño heterogéneo entre las que se interfiere la matriz fina y un suelo delgado $(20-30 \mathrm{~cm}$.) de incipiente grado de evolución.

$\mathrm{Al}$ pie de estas vertientes, allí donde los depósitos coluviales son más potentes, está teniendo lugar un intenso proceso de erosión remontante, con formación de profundos barrancos que dejan las raíces de los árboles al descubierto, lo que indica también que se trata de un fenómeno rápido. Ese proceso es mayor en aquellos sectores donde la erosión fluvial había quedado paralizada tras la formación de valles de obturación glaciar y que ahora han sido cortados por la erosión remontante. En tales condiciones pueden formarse amplias cabeceras activas por encima de los depósitos de obturación; en ellas predomina la escorrentía superficial sobre la infiltración; el mantillo es arrastrado y el transporte de cantos, muy activo, solamente se ve obstaculizado por las raíces al descubierto.

La evolución de las laderas en el bosque está relacionada sobre todo con las originales características de la infiltración y la escorrentía. No cabe duda de que el agua penetra más profundamente dentro del bosque (CHORLEY, 1980). La infiltración se ve favorecida por el mantillo orgánico y por las vías de acceso que suponen las raíces; incluso cuando éstas mueren quedan conductos por los que el agua se introduce aún más rápidamente. Este proceso es el que, de acuerdo con varios autores (WHIPKEY and KIRKBY, 1980, BAILLIE, 1975) se responsabiliza de la formación de pipes. Por otra parte, la escorrentía se ve sin duda limitada por el hecho de que las raíces más gruesas provocan la aparición de combamientos y depresiones en las que el agua se detiene hasta infiltrarse; y además, no hay que olvidar que la cobertera forestal intercepta parte de las precipitaciones (en torno 
a un $30 \%$ según ALVERA, 1977) lo que reduce las posibilidades de saturación superficial. Frente a la ausencia de deslizamientos, hallamos numerosos ejemplos de desprendimientos profundos, ligados a factores estructurales o de sobreexcavación glaciar (que originó vertientes con pendiente superior al límite de estabilidad del flysch).

Nos encontramos, en definitiva, en un medio en el que domina la infiltración profunda y en el que la escorrentía es esencialmente subcortical. De ahí la ausencia de una red de drenaje jerarquizada, lo que no excluye la existencia local de algunas rigolas, continuación aguas abajo de las que veíamos en el piso supraforestal ${ }^{9}$. Algunos canalillos poco profundos y aparentemente no muy funcionales indican que en ocasiones hay drenaje superficial aunque parecen tener un origen subcortical por su ausencia de cabecera. Acumulaciones locales de hojarasca y piñas señalan que existe un cierto arroyamiento difuso en los sectores de mayor pendiente.

Esa importancia de la infiltración profunda es la que justifica la modalidad de evolución de vertientes. En los niveles superiores del bosque, con suelos antiguos ricos en material fino, las laderas se ven sometidas a un intenso proceso de reptación, que se manifiesta en un incurvamiento generalizado de la base del tronco. Seguramente, los horizontes B y BC, más arcillosos, al recibir aportes hídricos adquieren un estado solifluidal y tienden a deslizarse en el sentido de la pendiente. Esto contribuye aún más a desorganizar cualquier intento de creación de una red de drenaje. Más hacia abajo la reptación se detiene o, al menos, disminuye en intensidad, pues los coluviones pedregosos son más estables. También es cierto que, lejos de las divisorias, dismunuyen las disponibilidades de agua y es menor también la acumulación de nieve por efecto eólico ${ }^{10}$.

La presencia aquí y allá de vías de saca de madera -que han llegado a profundizar hasta $2 \mathrm{~m}$. en los coluviones-y de pistas con sistemas brutales de drenaje ${ }^{\mathbf{1 1}}$ contribuye a diversificar más las vertientes cuyo rasgo más significativo, en ausencia de acciones

9. Este hecho excluye el que los rills supraforestales aparezcan por eliminación del bosque, pues también se dan en éste.

10. Es probable también que la reptación se vea en ocasiones favorecida por el dispositivo estructural, en vertientes donde el buzamiento de los estratos coincide con la pendiente y orientación de la ladera.

11. En las pistas construidas para prospecciones petrolíferas, por ejemplo, el sistema de drenaje consiste en una acumulación transversal de tierra que corta la escorrentía que fluye por la pista y dirige ladera abajo a través del bosque. 
antrópicas, es la tendencia a una estabilidad dinámica.

c) Los sistemas de erosión en áreas degradadas y de cultivos abandonados. Por debajo de $1.400 \mathrm{~m}$. - y aún mejor por debajo de $1.200 \mathrm{~m} .-$, especialmente en exposiciones solanas, el funcionamiento de las vertientes cambia por completo. La caracteristica común es la intervención humana que unas veces se ha limitado a eliminar el bosque, favoreciendo la colonización por el matorral, otras ha cultivado pendientes muy fuertes para abandonarlas al disminuir la presión demográfica y otras, en fin, ha ocupado fondos suaves y estables y terrazas colgadas, donde los problemas erosivos son despreciables. El resultado final es un cambio en la dinámica de vertientes al alterarse las condiciones de infiltración y de escorrentía y una pérdida local de parte o la totalidad del suelo. De todas formas conviene no perder de vista que no toda la erosión de estas laderas bajas tiene su origen en el hombre. Téngase en cuenta que en el postglaciar se ha venido produciendo un encajamiento de la red fluvial, tanto mayor en los valles afluentes que habian sido colmados por obturación glaciar. En éstos, una profunda garganta se encaja sobre el antiguo relleno horizontal, dejando a veces sólo pequeños cerros aislados (Escuer) y, en todo caso, provocando la aparición de espectaculares cárcavas en las morrenas laterales (valle de Aso). Ahora bien, este tipo de erosión geológica se centra en los canales fluviales y en cauces que a partir de los anteriores se reactivan por erosión remontante. Lo que sucede en las laderas atañe a los cambios in troducidos por el hombre en el paisaje.

Una segunda característica de todos estos ambientes es la enorme diversidad de procesos y formas. $Y$ esa diversidad se debe, por un lado, a razones físicas (variedad topoclimática y de depósitos de pie de vertiente, contrastes topográficos entre la base y las divisorias situadas entre 1.200 y $1.400 \mathrm{~m}$., herencias de relieves antiguos, influencia de la estructura), pero sobre todo a la heterogeneidad introducida por el hombre: los distintos usos del suelo sufridos a lo largo de la historia han dado lugar a situaciones muy diferentes.

En esa diversidad cabe distinguir la dinámica actual de los campos abandonados de la de las áreas repobladas, aunque algunos de los procesos coinciden en uno y otro caso (por ejemplo, los desprendimientos masivos).

En los campos abandonados conviene tener presente que la pendiente sólo se suaviza hacia la base, donde se ha construido un 
bancal de piedra. La erosión tiene lugar en los tramos de mayor pendiente, donde se aprecian signos de arroyamiento difuso (descalzamientos, pérdida de suelo) y donde en ocasiones se instalan rigolas aprovechando rupturas de pendiente. Ello no deja de ser normal por cuanto al abandonarse, la ausencia de laboreo y el apelmazamiento del suelo, dificultan la infiltración durante los primeros años. El resultado es un arrastre de materiales finos -quizás tan antiguo como la misma transformación en campo cultivado-que en sus casos extremos provocan la conversión de la ladera en un pedregal, al menos en superficie. Y este proceso es el que dificulta la instalación de cauces encajados en las vertientes, pues las piedras frenan el impacto de las gotas de lluvia, disipan la energía de la escorrentía y disgregan los hilillos de agua.

No obstante, los signos erosivos más destacados son los que tienen lugar por el desplome de los muros de piedra. El rellano originado por el muro frena sin duda la erosión pero es la causa del derrumbamiento por aumento de la infiltración. Una vez producida la caída se instala una rápida erosión remontante. Interesa además resaltar que un desplome suele ir acompañado de otros inmediatamente más abajo, pues el primero facilita la concentración del agua $\mathrm{y}$ el embebimiento ${ }^{12}$.

En las áreas repobladas las diferencias internas son mayores en la medida en que la repoblación afecta unas veces a antiguos campos cultivados, otras a matorral relativamente denso y otra a laderas totalmente degradadas. En todo caso, las modalidades de evolución actual tienen mucho que ver con la construcción de pequeños bancales en el momento de la plantación; estos bancales, que tratan de reducir la escorrentía superficial por aumento de la infiltración, poseen un escarpe pequeño (no más de $40 \mathrm{~cm}$.) y una anchura de hasta $4 \mathrm{~m}$. Cuando se trata de solanas con pendiente superior al $30 \%$ son áreas muy pedregosas lo que, como en el caso anterior, dificulta la concentración de agua y la formación de rigolas. Estas piedras proceden de los afloramientos de areniscas que, formando pequeños frentes de cuesta, alternan con las margas.

No obstante, ello no impide totalmente el que haya escorrentía. Pequeños canales atraviesan las fajas originando ocasionalmente

12. Es problable -y aquí lo planteamos sólo como hipótesis- que el dominio de un clima más humedo aquí que en Sobrarbe sea la razón por la que en el Alto Aragón Occidental no se hicieran auténticos bancales, que hubieran tendido a autodestruirse por exceso de humedad. 
microconos de deyección sobre la faja inmediatamente inferior. Sin duda, la poca permeabilidad del suelo, elaborado por alteración de margas, reduce la infiltración, y de ahí que el agua desborde por el escarpe del bancal encajándose. Más normal es la evolución de las fajas por solifluxión; sobre los rellanos de los bancales se observan pequeños lóbulos de hasta $1 \mathrm{~m}^{2}$, en un intento por eliminar las irregularidades artificiales de la vertiente. En todo caso tampoco son frecuentes las rigolas y cárcavas encajadas -salvo las procedentes de la parte baja por erosión regresiva- y el arroyamiento difuso, acompañado de rigolas que cambian de posición con frecuencia, es el mecanismo más habitual de evolución ${ }^{13}$.

De forma intercalada y afectando a repoblados, matorral y campos abandonados se observan cicatrices de grandes desprendimientos. Suelen situarse por debajo de pequeños rellanos o tramos de vertiente con menos pendiente y ofrecen una variada gama de tamaños. Estos procesos tienen lugar bajo diferentes condiciones:

- Influencias estructurales, en sectores fallados o donde lo favorece la disposición de los estratos, pero en especial allí donde las capas margosas son más potentes.

- Socavamiento de orillas por divagación lateral de la red fluvial, lo que da lugar a un incremento de gradiente y a una pérdida de resistencia frente a la fuerza de gravedad (BRUNSDEN, 1979); asimismo, en este grupo se incluyen los desprendimientos originados por la formación de una artesa glaciar (valle del Gállego).

- Circulación subterránea del agua, favorecida por el rellano superior. Cuando este último es de reducidas dimensiones, el desprendimiento también lo es, originando una colada de barro y piedras que se pierde a media ladera. Por el contrario, cuando el rellano es mayor (incluso varias decenas de hectáreas), entonces se forman grandes desprendimientos (debris flows) que alcanzan el fondo del valle. Ello sucede, por ejemplo, en torno a niveles cuaternarios antiguos, de perfil suave y con excelentes condiciones para que se infiltre el agua de lluvia. Los mejores modelos se dan en el borde meridional del flysch, alli donde existen antiguas cabeceras de barrancos de forma semicircular y fondo suave relleno por un potente manto de materiales de solifluxión (BARRERE, 1966). En la cabe-

13. Mediante esos procesos se ha eliminado toda o parte de la cobertera edáfica, apareciendo así bojes descalzados, síntoma a su vez de que se trata de un fenómeno relativamente reciente, al menos en sus fases más intensas. 
cera de Espuéndolas se identifican dos coladas, la última de las cuales es posterior a 1957.

Una vez se ha abierto la cicatriz, evoluciona por rigolas que se integran y subdividen y, frecuentemente, por microcoladas margosas (mud flows) en los momentos de precipitaciones prolongadas. En la actualidad las grandes cicatrices siguen evolucionando al formarse a su alrededor grietas que siguen las curvas de nivel y que sospechamos se ven aceleradas por las fajas de repoblación ${ }^{14}$.

Cuando los debris flows son numerosos no son sólo un proceso de evolución de vertientes. Al llegar a la red fluvial, ésta se encuentra con una sobrecarga extraordinaria de piedras que difícilmente puede evacuar. El fenómeno adquiere mayor relevancia cuando barrancos recientes remontan su cabecera y acceden a campos abandonados muy pedregosos, que abastecen así de cantos a los ejes de drenaje. En estas condiciones, los ríos alteran su equilibrio y dinámica y pasan a ser anastomosados, de los que en el mapa pueden verse numerosos ejemplos (Estarrún, Lubierre, Ijuez, el mismo Gállego). Un enorme canturral ocupa todo el lecho, por el que frecuentemente se pierden las aguas, y numerosos canales abandonados son exponente de su torrencialidad. Algunos de estos ríos anastomosados parecen relativamente recientes, pues en ocasiones incorporan árboles vivos o recubren parcial o totalmente construcciones humanas ${ }^{15}$, lo que parece sugerir una influencia de acciones antrópicas más que un cambio climático.

\section{Conclusiones}

En el flysch surpirenaico pueden distinguirse dos grandes sistemas morfogenéticos, uno nival y otro pluvial, aunque tales denominaciones tienen carácter reservado y operativo únicamente dentro de la región estudiada. E1 tránsito entre ambos sistemas tiene lugar alrededor de los $1.600 \mathrm{~m}$. de altitud y coincide apreciablemente con la isoterma de $0^{\circ}$ durante el período diciembre-marzo.

El sistema nival está muy controlado por procesos de periglaciarismo mitigado que acompañan a la fusión lenta y precoz de la nieve.

14. No olvidemos que los bancales aumentan la infiltración y disminuyen, por tanto, la resistencia de la vertiente frente a la fuerza de gravedad.

15. Por ejemplo, la ermita de San Adrián de Sasave (siglo XII), visible ahora después de que se le ha eliminado un potente man to de piedras. 
En condiciones de suelo profundo y vegetación cerrada predominan los movimientos masivos, principalmente solifluxión y deslizamientos superficiales. Una vez desmantelado el suelo se instalan procesos erosivos controlados por escorrentía superficial y prácticamente se bloquea la edafogénesis. Algunas de las formas observadas (rigolas, grandes lóbulos de solifluxión, vertientes regularizadas) parecen heredadas de otros sistemas morfogenéticos.

El sistema pluvial está dominado por las precipitaciones líquidas sobre suelo saturado, las que ocurren a fin de otoño e invierno. Por otra parte, la acción del hombre aparece en este sistema como el principal factor que controla el sentido de los procesos erosivos. Cuando aquélla es débil y se conserva una vegetación cerrada con mantillo orgánico, predominan también los movimientos en masa, reptación lenta o desprendimientos locales profundos controlados por la estructura del flysch: más frecuentes en áreas falladas o fracturadas.

La gestión agraria tradicional, eminentemente cerealista, dio lugar a un tipo de arroyamiento difuso donde coexisten los movimientos masivos de carácter muy somero con la escorrentía superficial. Esta última va lavando de finos el horizonte superior del suelo, desarrollando sobre él una armadura de cantos. En el marco general de este tipo de erosión, se forman rigolas permanentes cuando aumenta la pendiente, o proliferan los desprendimientos donde se favorecen concentraciones locales de agua.

Superpuestos a los sistemas erosivos en laderas que acabamos de resumir, se observa en el flysch otro conjunto de procesos derivados del encajamiento postglaciar de la red fluvial. Este hecho, acentuado a veces por la ruptura de los muros merrénicos que cerraban valles laterales, desestabiliza los márgenes y cabeceras desmantelándolos por desprendimientos. Tales procesos, especialmente importantes en morrenas, depósitos coluviales y relieves seniles colgados, son los principales responsables de la acumulación de gravas en los cauces y de los picos de carga en suspensión.

Las medidas antierosivas en un territorio como el flysch no deben limitarse al control de la escorrentía superficial. Hemos visto que los movimientos masivos asociados al flujo subcortical constituyen un factor básico de los sistemas morfogenéticos. En consecuencia resulta esencial obstaculizar la convergencia de las aguas infiltradas hacia determinados puntos, especialmente si se trata de coluviones o áreas fracturadas de poca coherencia. 


\section{BIBLIOGRAFIA}

ALVERA, B., 1975: Intercepción de las precipitaciones atmosféricas en un pinar al toaragonés. Pirineos, 8: 7-13, Jaca.

ANGLADA, S., BALCELLS, E., CREUS, J., GARCIA-RUIZ, J.M., MARTI BONO, C. y PUIGDEFABREGAS, J., 1980: La vida rural en la montaña española. Instituto de Estudios Pirenaicos, 113 pp. Jaca.

BAILLIE, I.C., 1975: Piping as an erosion process in the uplands of Sarawak. The Journal of Tropical Geography, 41: 9-15, Singapore.

BARRERE, P., 1963: La période glaciare dans l'ouest des Pyrénées centrales franco-espagnoles. Bull. Soc. Geol. Fr., 7: 516-526, Paris.

BARRERE, P., 1966: La morphologie quaternaire dans la région de Biescas et de Sabiñánigo (Haut Aragón). Bull. Ass. Fr. Et. Quat., 2: 83-93, Paris.

BRUNSDEN, D., 1979: Mass movements. Process in Geomorfology (EMBLETON and THORNES, Eds.). E. Arnold, 130-186, Londres.

CHORLEY, R.J., 1980: The hillslope hydrological cycle. Hillslope Hydrology, Ed. M.J. KIRKBY, John WILEY, pp. 142, Londres.

CREUS, J., 1977: El clima del Alto Aragón Occidental. Tesis Doct. Universidad de Navarra: 421 pp. Pamplona.

CREUS, J. y PUIGDEFABREGAS, J., 1978: Influencia del relieve en la distribución de las precipitaciones máximas: un ejemplo pirenaico. Cuadernos de Investigacion (Geografia e Historia) 4 (1): 11-23, Logroño.

DE LEON, A., et al, 1976: Caracterización agroclimática de la provincia de Huesca. Ministerio de Agricultura, 51 pp., 25 tablas y 32 mapas, Madrid.

ELIAS, F., 1963: Precipitaciones máximas en España. Ministerio de agricultura. Servicio de Conservación de Suelos: 266 pp, Madrid.

GARCIA-RUIZ, J.M. y ARBELLA, M., 1981: Modelos de erosión en el piso subalpino: la degradación de los loess del macizo de Monte Perdido. Pirineos, 114: 35-58, Jaca.

GARCIA-RUIZ, J.M., PUIGDEFABREGAS, J., CREUS, J. (en prensa). Los recursos hidricos superficiales de la provincia de Huesca. Diputación provincial de Huesca.

LISO PUENTE, M. y ASCASO LIRIA, A., 1969: Introducción al estudio de la evapotranspiración y clasificación climática de la cuenca del Ebro. Anales de Aula Dei (C.S.I.C.) 10 (12): 565 pp., Zaragoza. 
MARTI BONO, C., 1977: Altos valles de los ríos Aragón y Gállego. Actas II Reun. Grup. Cuat., 337-348, Madrid.

MARTI BONO, C., SERRAT, D. y GONZALEZ, M.C., 1978: Los fenómenos glaciares en la vertiente meridional de los Pirineos. $V$ Coloquio de Geografia, 67-74, Granada.

PUIGDEFABREGAS, J., 1969: Avance para un estudio climatológico del Alto Aragón. Pirineos, 79-80: 115-140, Jaca.

PUIGDEFABREGAS, J., 1979: Características de la inversión térmica en el extremo oriental de la depresión interior alto aragonesa. Pirineos, 96: 21-50, Jaca.

PUIGDEFABREGAS, J. y CREUS, J., 1976: Pautas espaciales de variación climática en el Alto Aragón. Pirineos, 7 (1): 23-24, Jaca.

PUIGDEFABREGAS, J. y CREUS, J., 1978: Climas topográficos en montaña: un ejemplo en el macizo de San Juan de la Peña (Huesca). Avances sobre la investigación en bioclimatología. Publ. Centro de Edafología y Biología aplicada de Salamanca: 72-84, Salamanca.

PUIGDEFABREGAS, J. y GARCIA-RUIZ, J.M. (en prensa): Glissements massifs au niveau supraforestier dans les Pyrénées Centrales. Ecologie et Biogéographie des Milieux Montagnards, Laruns.

SOKAL, R.R. y ROHLF, F.J., 1969: Biometry. Fréeman: 776 pp.

SOUTADE, G., 1980: Modelé et dynamique actuelle des versants supraforestiers des Pyrénées orientales. Imprimerie Cooperative du Sud-Ouest, 452 pp, Albi.

WHIPKEY, R.Z. and KIRKBY, M.J., 1980: Flow within the soil. Hillslope Hydrology, Ed. M.J. KIRKBY, John Wiley, Londres. 


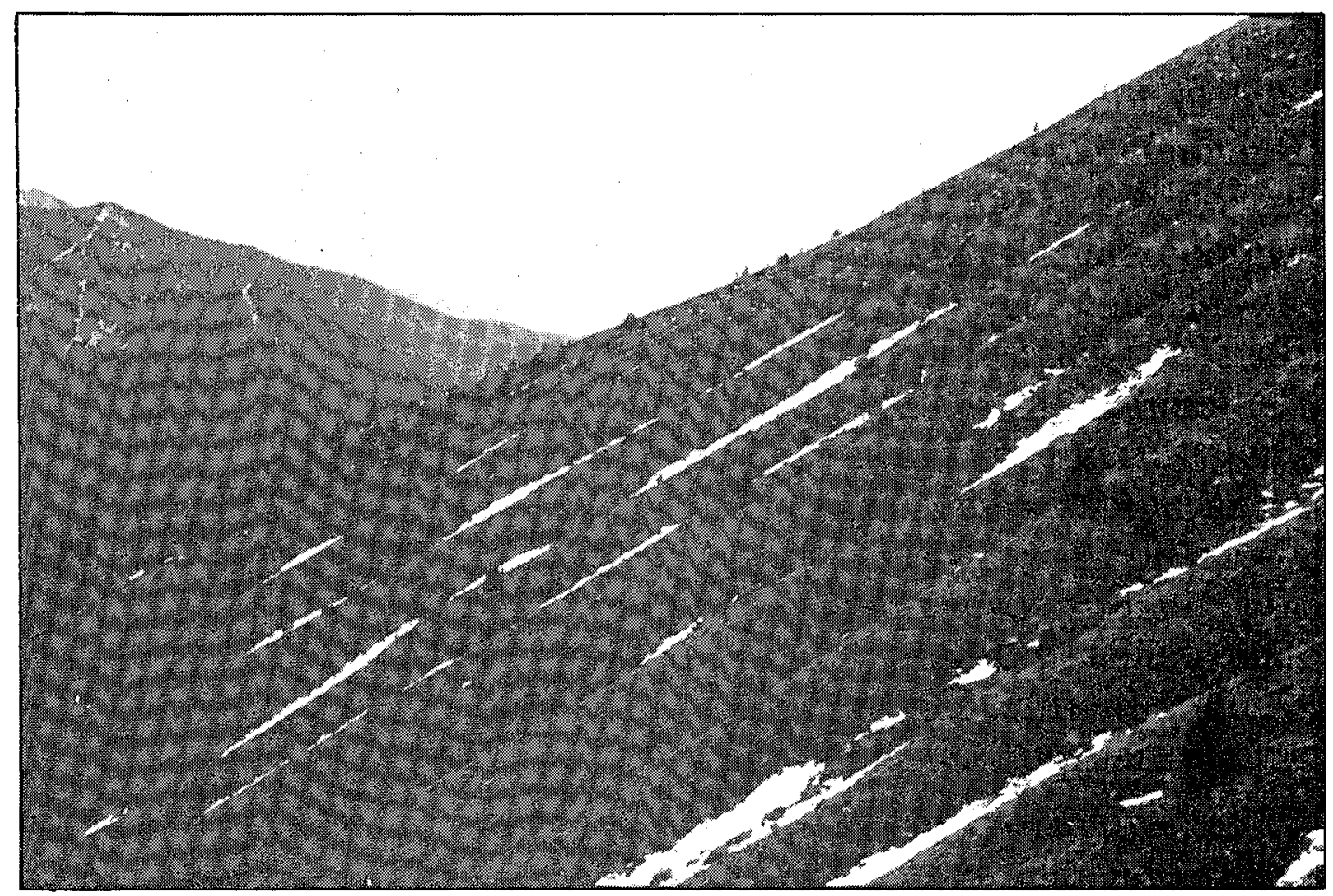

FOTO 1

Rigolas en el barranco del Puerto (valle del Gállego). Cauces paralelos sin apenas integración.

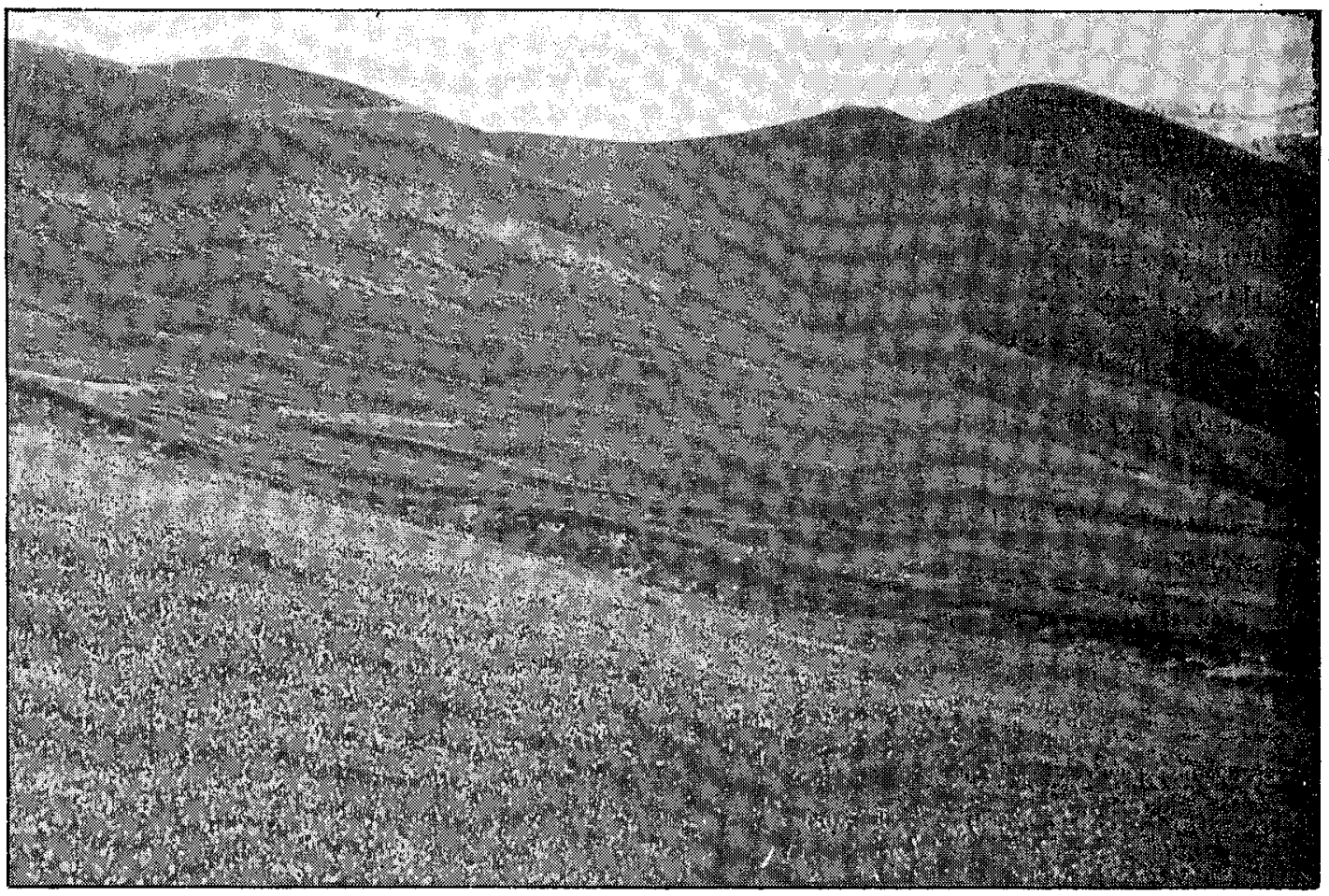

\section{FOTO 2}

Solifluxión en rellano con suelo profundo y pasto mesófito. En las áreas de mayor pendiente el suelo ha desaparecido y predomina la erosión laminar. 


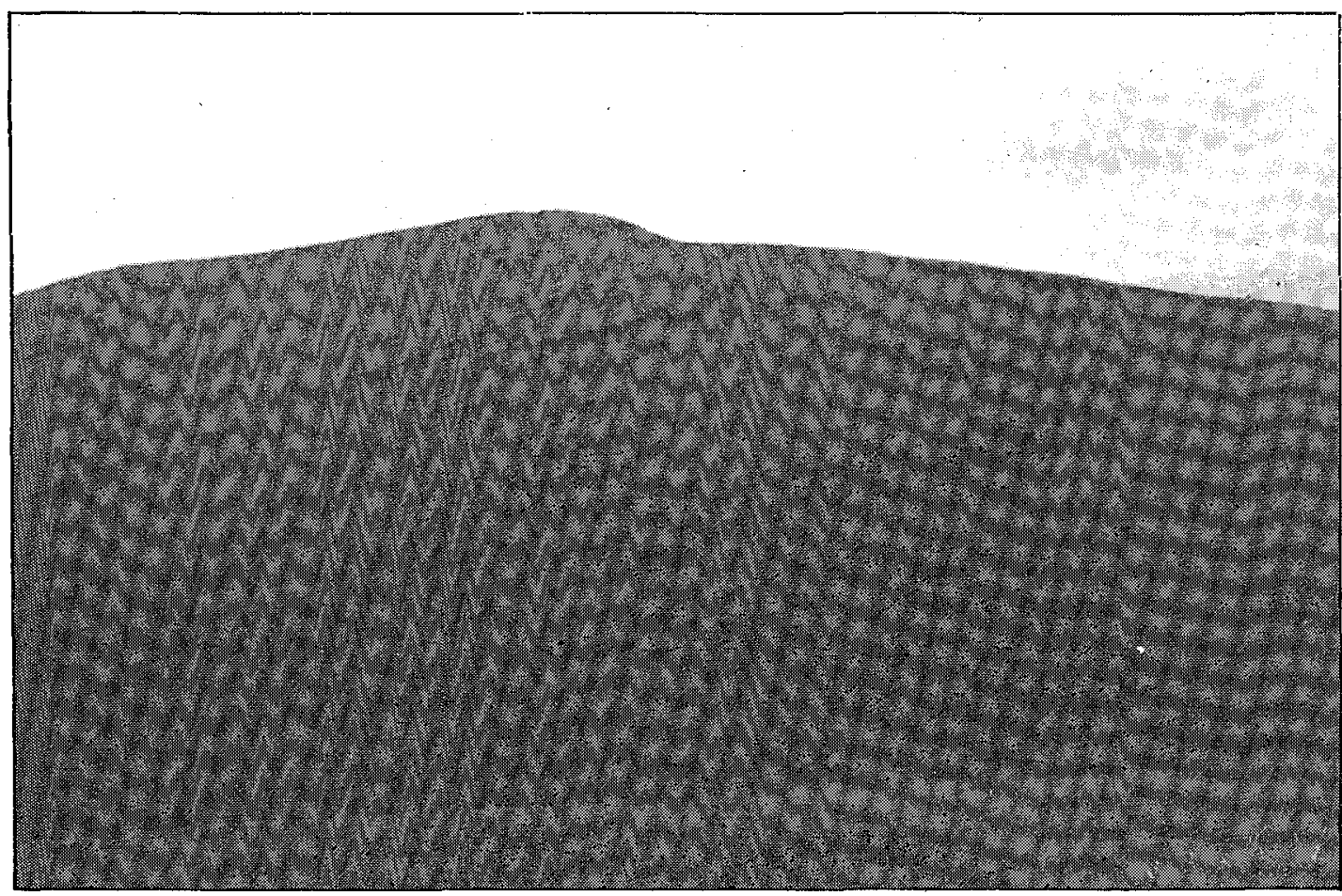

FOTO 3

Cicatrices de deslizamientos en la Sierra de Otal, sobre suelos profundos.

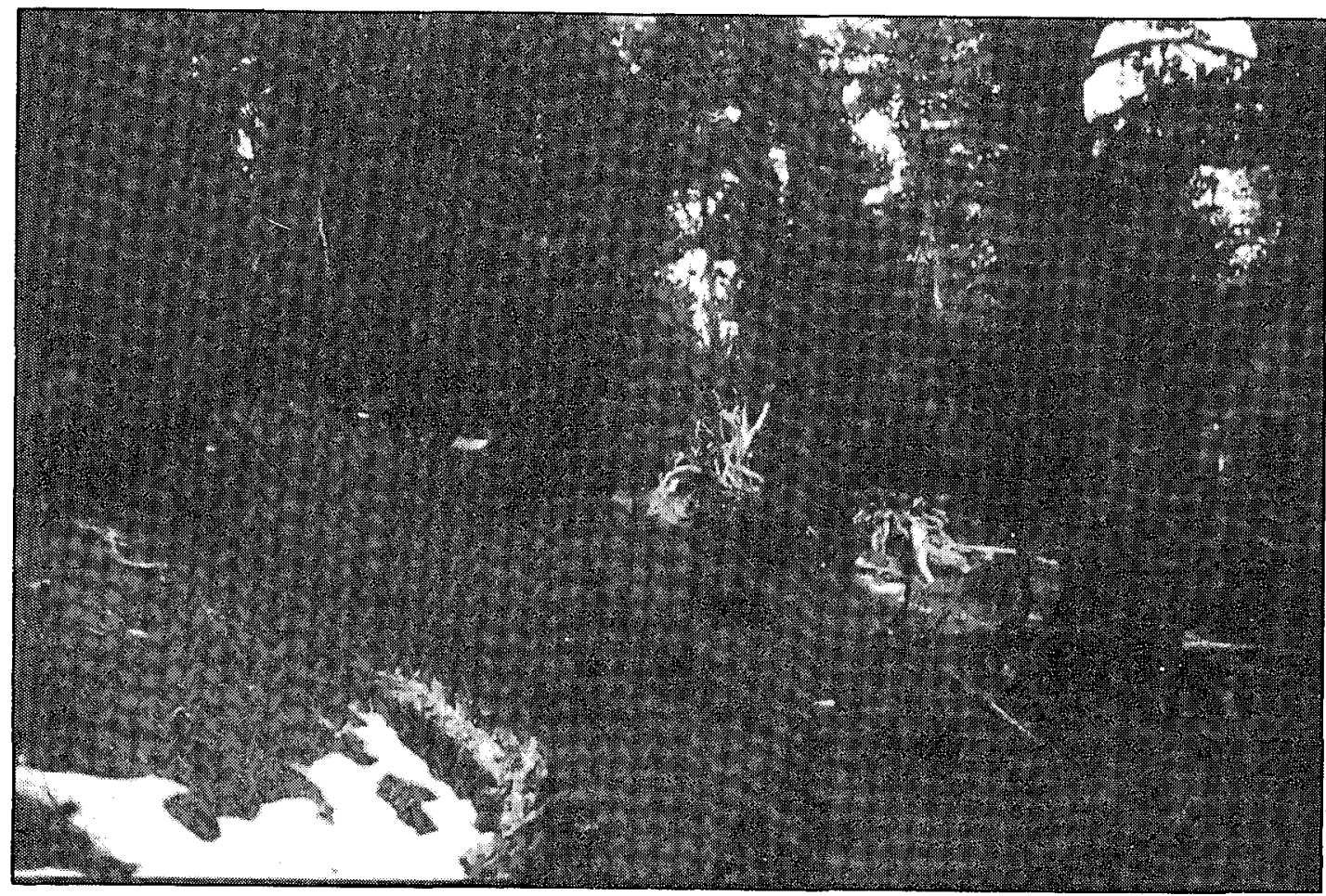

FOTO 4

Reptación en medio forestal (valle de Aso). 


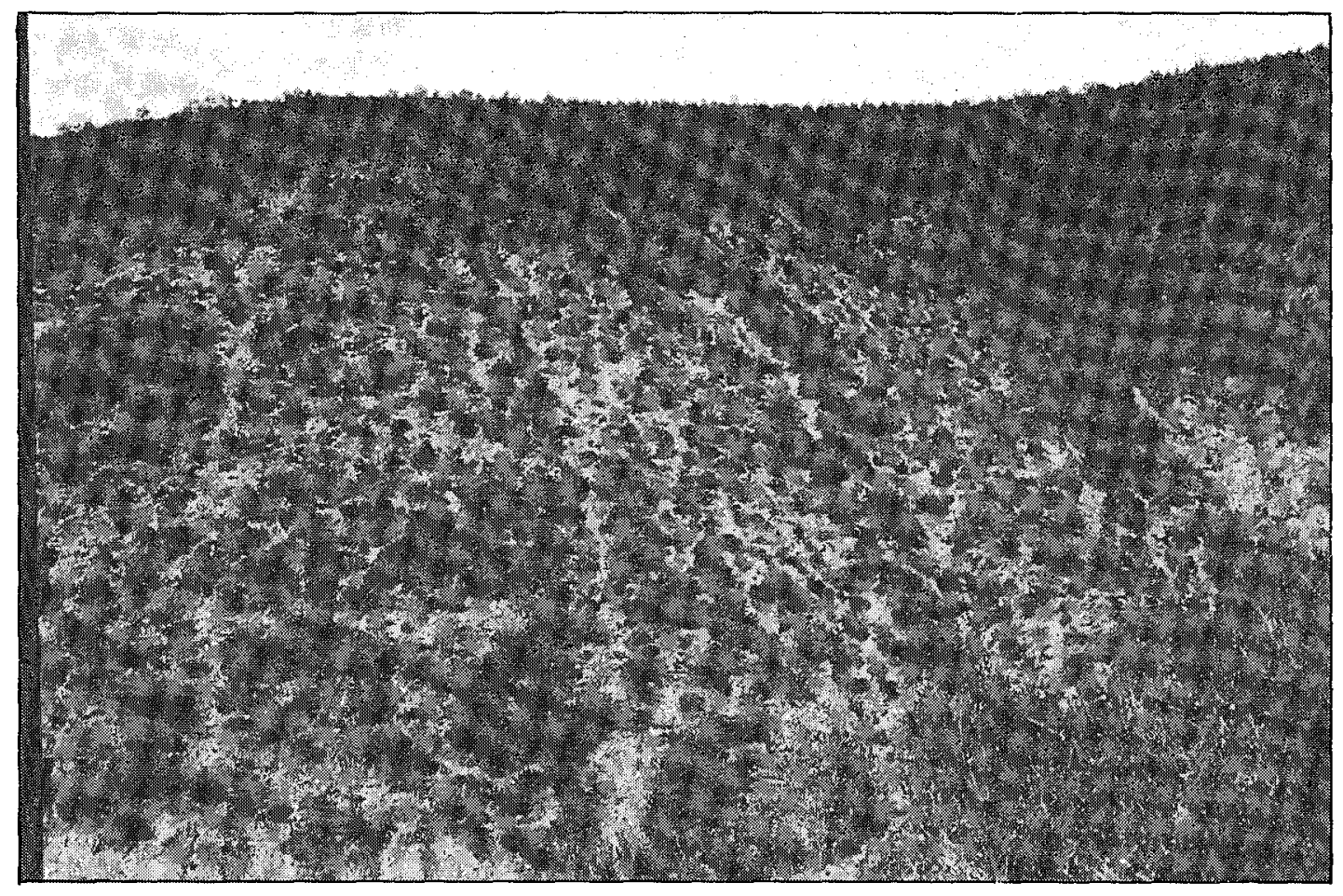

FOTO 5

Rigolas de ambiente submediterráneo en Aratorés.

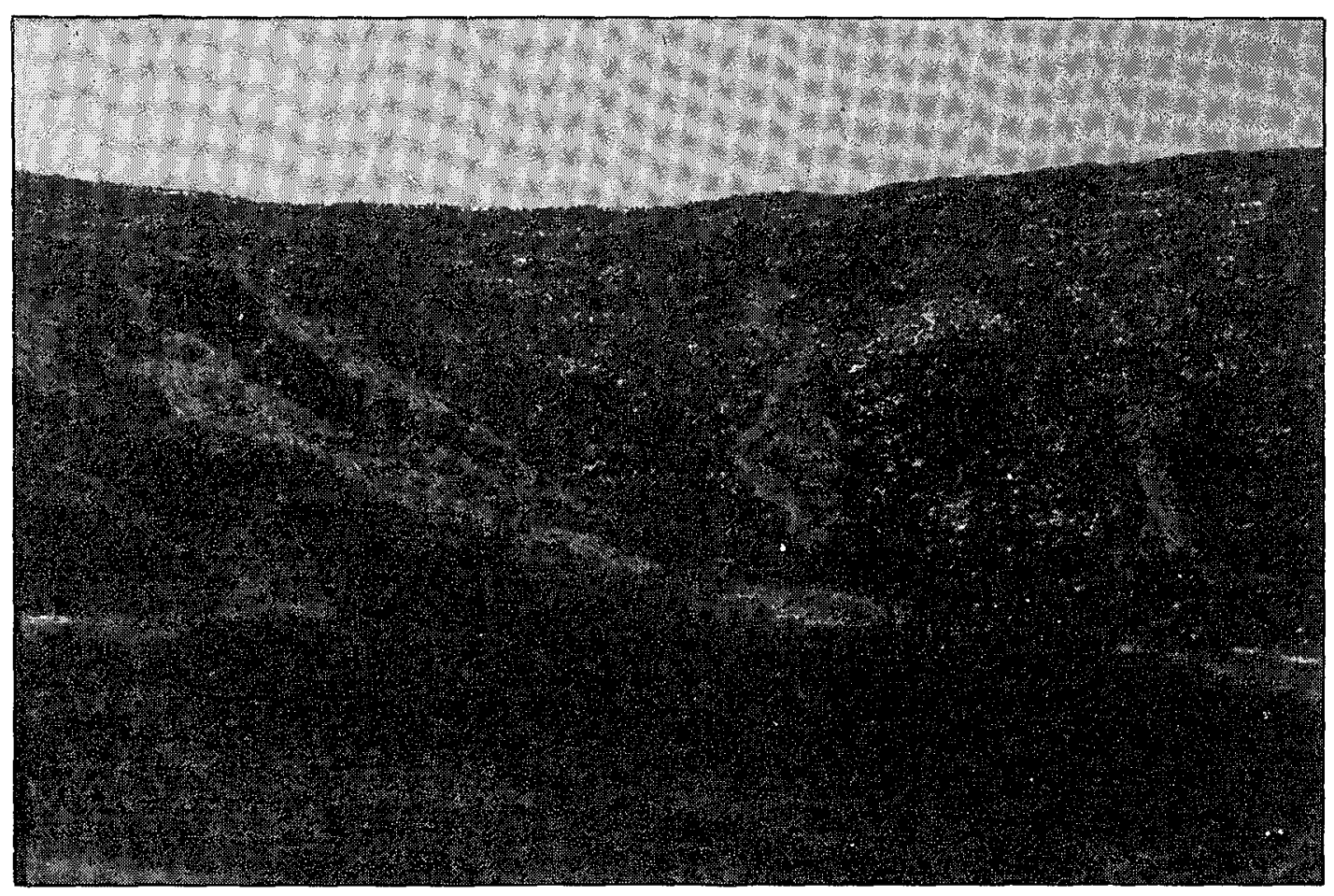

FOTO 6

Desprendimientos (mudflows) en el límite meridional del flysch. 


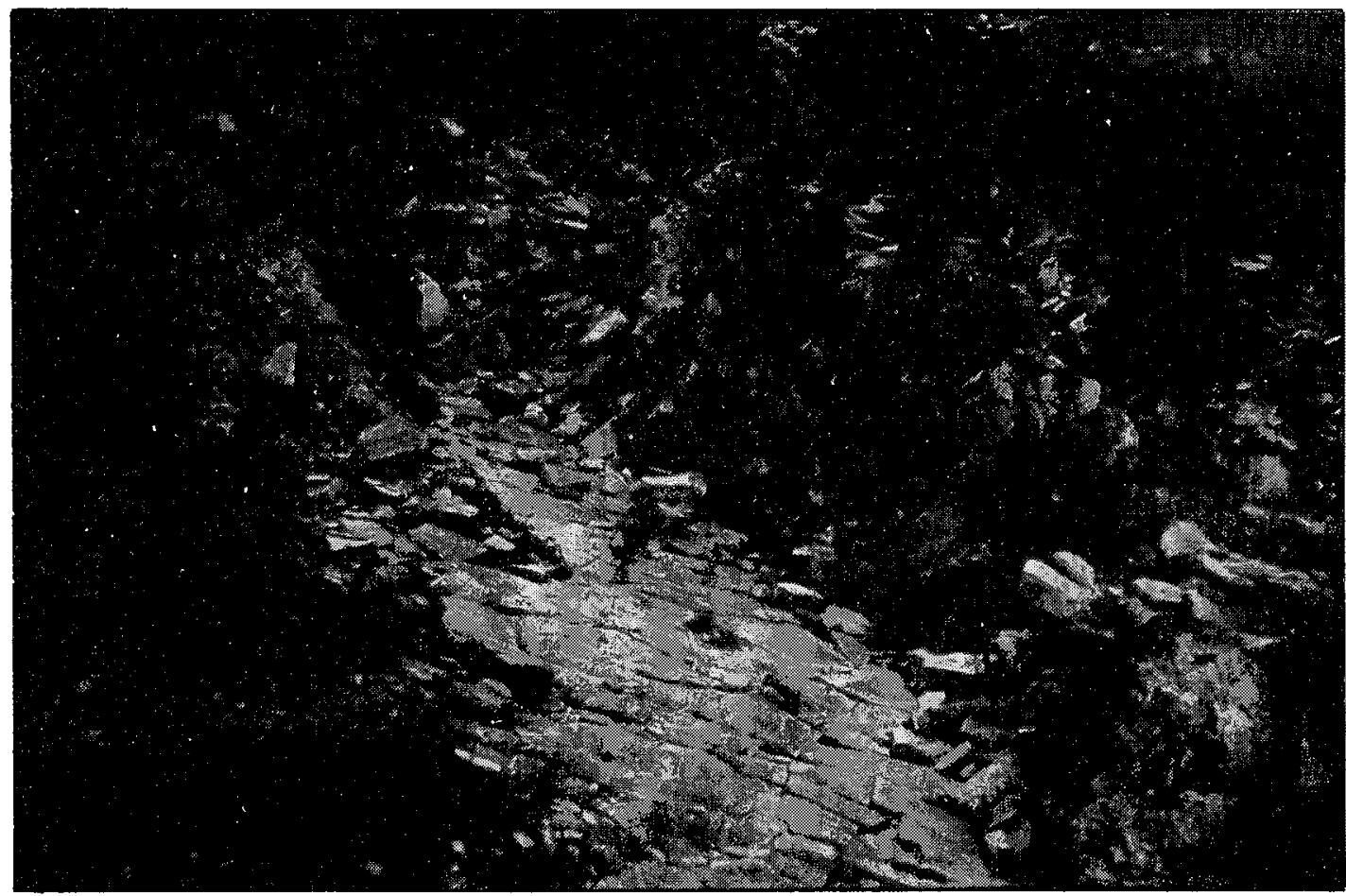

\section{FOTO 7}

Barranco inscrito sobre ladera antaño cultivada. La incisión desmantela el suelo y las margas y se detiene al llegar a las areniscas.

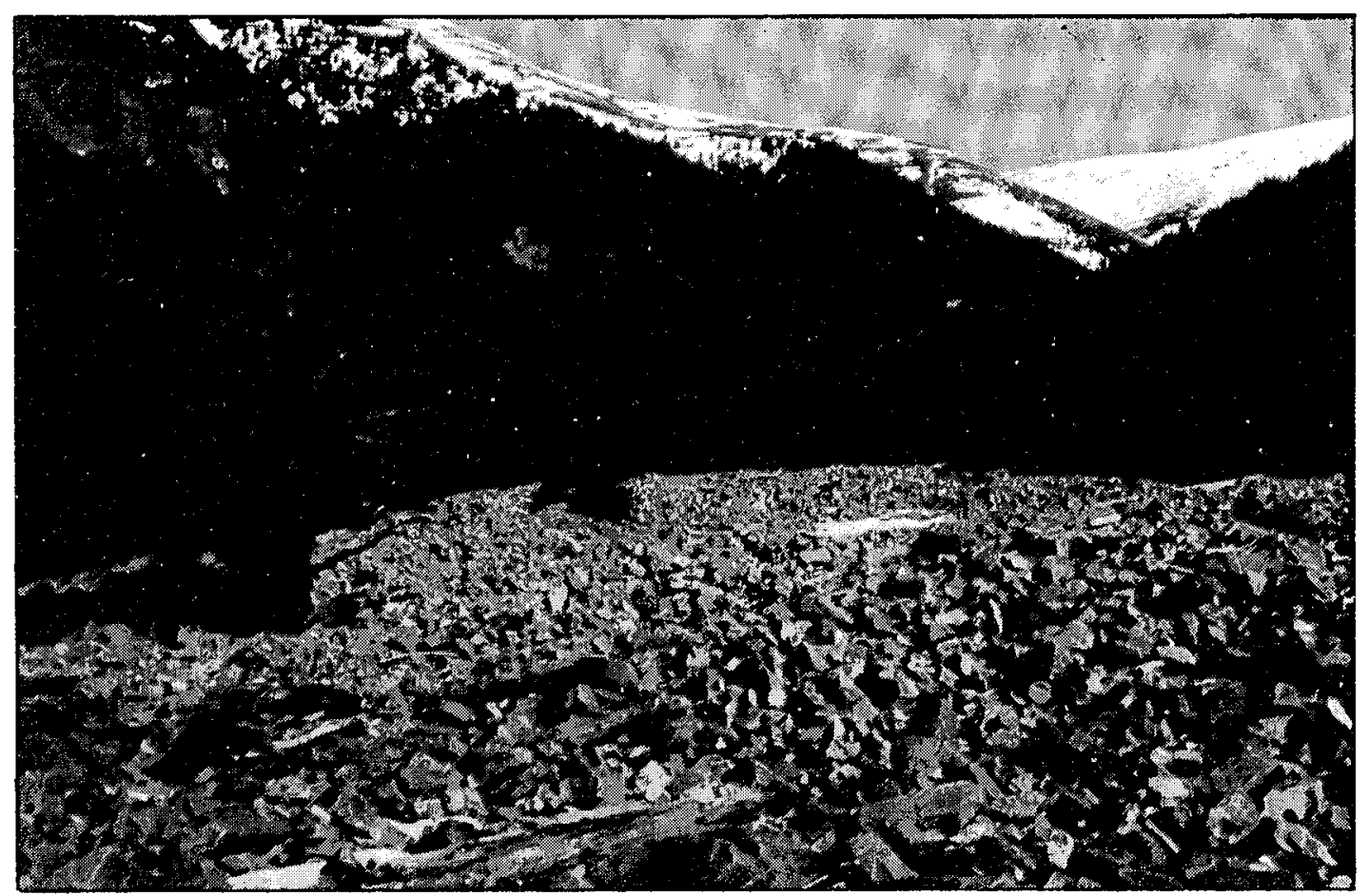

\section{FOTO 8}

Lecho del barranco de Ijuez, con gran acumulación de piedras y pinos semienterrados. 